\title{
Learned Changes of Feeding Behavior in Aplysia in Response to Edible and Inedible Foods
}

\author{
Abraham J. Susswein, Miriam Schwarz, and Esther Feldman \\ Department of Life Sciences, Bar-llan University, Ramat-Gan 52 100, Israel
}

Feeding behavior in Aplysia fasciata and $A$. oculifera is modified by pairing the behavior with reinforcing consequences. Successful and unsuccessful attempts to transfer food from the buccal cavity to the crop act as positive and negative reinforcers, respectively. A number of changes in feeding behavior occur as a result of pairing of feeding with the negative reinforcer: (1) feeding responses become less effective in leading to the entry of food into the buccal cavity; (2) when food does enter the buccal cavity, it exits sooner; (3) swallowing responses after food entry are less likely to occur; (4) Aplysia eventually cease responding to food. Pairing successful transfer of food into the crop with feeding behavior produces opposite effects. Behavioral change is specific to pairing, as shown by lack of change when reinforcement is explicitly unpaired with feeding behavior. Behavioral change is specific to foods with a particular taste and texture; generalization to alternate foods was not observed. In spite of cessation of feeding, animals remain aroused, as shown by low response latency to alternate foods. Memory of response change persists for at least $48 \mathrm{hr}$.

In recent years, a number of laboratories have begun to investigate the neural basis of associative learning in Aplysia (Carew et al., 1983; Kandel and Schwartz, 1982; Lukowiak and Sahlcy, 1981; Walters and Byrne, 1983; Walters et al., 1979, 1981) and other gastropod molluscs (Alexander et al., 1982; Alkon, 1980; Audesirk et al., 1982; Chang and Gelperin, 1980; Crow, 1983; Crow and Alkon, 1980; Davis and Gillette, 1978; Davis et al., 1983; Gclpcrin, 1983). These studies attempted to explain learned behavioral changes in terms of the properties of specific cells participating in the behavior. Since the mechanisms underlying learning are likely to vary or may be present in different circuit elements in circuits designed for different behaviors, studying a variety of paradigms may provide insight into how general a mechanism is and may generate rules of where in a circuit particular features that lead to pairing-specific plasticity are inserted.

An effective strategy for studying the neural basis of associative learning has been to map a neural circuit, determine the properties of its component cells, and then find a learning paradigm involving the circuit. Beginning with a circuit and then proceeding to behavior plays to the strength of gastropods, their nervous systems; however, a priori it is impossible to predict whether learning occurs in a given circuit or which stimuli or response parameters are relevant to learning.

The present study grew out of an attempt to find a task that

Received Dec. 10, 1984; revised July 2, 1985; accepted July 3, 1985.

We would like to thank Irving Kupfermann and Jeffrey Camhi for comments on an earlier version of the manuscript. This work was supported in part by Israel Institute for Psychobiology - Charles E. Smith Family Foundation Grant No. 7/84.

Correspondence should be addressed to Dr. A. Susswein at the above address. Copyright $\odot 1986$ Society for Neuroscience $0270-6474 / 86 / 051513-15 \$ 02.00 / 0$
Aplysia could readily learn and to find the relevant circuit after learning was shown to occur. Feeding was chosen for study because it is a well-described (Kupfermann, 1974), easily observed behavior; in addition, it is likely that the appropriate circuit elements are accessible. Feeding in Aplysia has been studied extensively as a model for investigating control of a complex motor system (Cohen et al., 1978; Jahan-Parwar and Fredman, 1983; Jahan-Parwar et al., 1983; Kupfermann, 1974; Preston and Lee, 1973). Feeding comprises at least three separate movements:

1. Biting, consisting of a protraction-retraction sequence of the buccal mass, coupled with inward rotation and closing of the radula; biting leads to entry of food into the mouth (Kupfermann, 1974).

2. Swallowing, consisting of a retraction-protraction sequence, coupled with radular opening; swallowing leads to transfer of food from the buccal cavity to the esophagus (Kupfermann, 1974).

3. Rejection, consisting of a protraction-retraction sequence similar to that of biting but with radular movements pushing food out of the mouth, rather than pulling it in (B. Kuslansky and I. Kupfermann, personal communication).

Effects of motivational variables such as arousal (Kupfermann, 1974; Kupfermann and Weiss, 1982; Susswein et al., 1978; Weiss et al., 1981) and satiation (Kupfermann, 1974; Kuslansky et al., 1978; Susswein and Kupfermann, 1975a, b; Susswein et al., 1976) have been particularly well documented, and cellular neurophysiological correlates for some of these effects have been demonstrated (Kupfermann and Weiss, 1982; Rosen et al., 1979, 1982a; Weiss et al., 1978, 1979, 1981). Feeding in other gastropods has also been examined for largely similar reasons (Benjamin and Rose, 1979; Davis et al., 1974, 1977; Gelperin et al., 1978; Kater, 1974; Lee et al., 1974; Reingold and Gelperin, 1980; Rose and Benjamin, 1979; Susswein and Bennett, 1979; Susswein et al., 1984a; Willows, 1978, 1980). Feeding can also be modified by classical conditioning (Alexander et al., 1982; Audesirk et al., 1982; Gelperin, 1975; Mpitsos and Collins, 1975; Sahley et al., 1981 a, b), and the neural basis of classical conditioning has been examined (Chang and Gelperin, 1980; Davis and Gillette, 1978; Davis et al., 1983).

In a preliminary report (Susswein and Schwarz, 1983), we described a learned change in Aplysia feeding behavior. The present work examines this phenomenon in greater detail. This paper documents the changes in behavior that occur during learning and demonstrates that the phenomenon has much in common with instrumental learning. The following paper (Schwarz and Susswein, 1986) demonstrates that regulation of feeding by learning occurs via mechanisms different from those underlying other forms of modification of feeding and identifies a neural pathway conveying reinforcing stimuli to the CNS.

Preliminary investigations (Susswein and Schwarz, 1983) demonstrated that Aplysia cease to feed when feeding responses are paired with stimuli arising from failed attempts to consume 


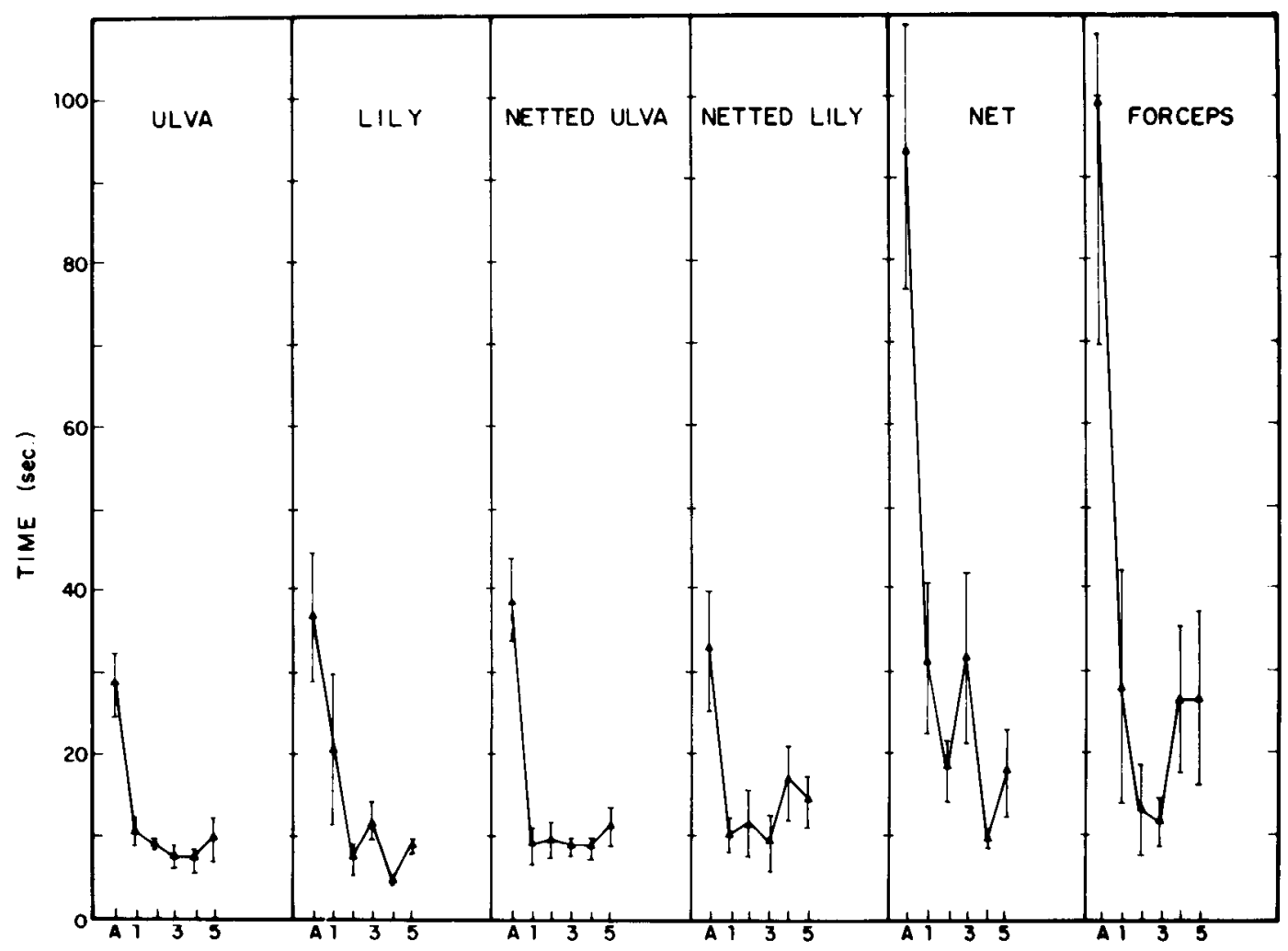

Figure 1. Arousal of feeding with netted and non-netted Ulva and lily, and with net alone and forceps. Arousal latency to respond to the initial touch of the food substance to the lips is shown $(A)$, as are the time intervals from the first to the sixth successive responses to food, making five interresponse intervals (1-5). SE are shown. Data are from $A$. fasciata.

food (Susswein and Schwarz, 1983). The present paper examines in greater detail the regulation of feeding by stimuli arising from the consequences of feeding behavior. The paradigm is of interest, since it has much in common with instrumental learning, while other associative tasks under study in gastropods more closely resemble other forms of learning (Carew et al., 1981, 1983; Crow and Alkon, 1980; Gelperin, 1975; Lukowiak and Sahley, 1981; Mpitsos and Collins, 1975; Sahley et al., 1981a, b; Walters and Byrne, 1983; Walters et al., 1979, 1981). The present study therefore provides an opportunity to begin to examine whether neural mechanisms underlying different forms of learning may be related.

In instrumental learning, a behavior is altered by pairing the behavior with reinforcing consequences. Performance of the behavior can be increased or decreased, based on whether the reinforcement is positive or negative. Specific discriminative stimuli can control the behavior by signaling to the animal that a particular response-reinforcement relationship is in operation (Reynolds, 1975). The present paper shows that feeding behavior can be modified by pairing the behavior with positive and negative reinforcers. Failed attempts at food consumption serve as negative reinforcers, while successful food consumption acts as a positive reinforcer. Behavioral change is specific to foods having a particular combination of taste and texture.

\section{Materials and Methods}

Aplysia fasciata weighing 75-250 gm were collected along the Mediterranean coast of Israel; $A$. oculifera weighing $10-80 \mathrm{gm}$ were collected at Elat, on the Red Sea coast of Israel. The species used in each experiment is in each case indicated below.

Both $A$. fasciata and $A$. oculifera are seasonally available along the Israeli coasts (Gev et al., 1984), precluding use of either species yearround. In every case, the species used for a particular experiment is noted. Preliminary analyses indicated that most parameters of feeding are unaffected by seasonal variables; an exception is time to criterion for learning (M. Schwarz and A. J. Susswein, unpublished observations). The data presented below were collected throughout the period that each species was available. Detailed analysis of motor patterning during negative reinforcement is from a group of $20 \mathrm{~A}$. fasciata trained during September and October 1982, and six A. oculifera trained in March and April 1983. Experiments on positive reinforcement were performed during February and March 1984. Nonparametric statistical tests were generally used for quantification of motor patterning during learning, since these data showed a large heterogeneity of variance.

Animals were individually housed in plastic mesh cages suspended in 940 liters of recirculating, filtered Mediterranean seawater maintained at $17^{\circ} \mathrm{C}$ (specific gravity, 1.025). Animals were food-deprived for $1-2$ weeks before use. A 12:12 light-dark schedule was used. Experiments wcre performed during the dark phase, since $A$. fasciata are nocturnally active (Susswein et al., 1983); it is not known whether $A$. oculifera are active diurnally or nocturnally. To observe animals, room lights were turned on immediately prior to an experiment and were shut off afterward.

Food was either thalli of the green alga Ulva lactuca or leaves of the vascular plant of the lily family, Hemerocallis fulva. Ulva is a natural food highly favored by the animals (Susswein et al., 1984a). Ulva was generally stored frozen in the laboratory and thawed immediately before use; in some cases, fresh Ulva was used, with no difference in results. The lily grows on the campus of Bar-Ilan University and was freshly picked at the start of each experiment.

In most experiments, food was wrapped in plastic netting composed of woven strands of $0.32 \mathrm{~mm}$ diameter polyethylene; holes in the netting werc $1.5 \mathrm{~mm}$ long per side. Inedible netted food was prepared for $A$. fasciata by cutting a square of net $3.0 \mathrm{~mm}$ long on each side. Because $A$. oculifera is a smaller animal, the net for this species was $2.2 \mathrm{~cm}$ on each side. Food was placed in the center of the square, and the square was folded $3 \times$, producing an arrowhead-shaped structure, with food centered at the tip behind a layer of net. The folds were held in place by clamping the folded net in a hemostat. Sharp edges of strands of the net were cut away, and the netted food at the end of the hemostat was used as a stimulus for feeding. The length of netted food was $1-1.5 \mathrm{~cm}$ for $A$. fasciata, and $0.5-1.0 \mathrm{~cm}$ for $A$. oculifera, more than enough to prevent the metal of the hemostat itself from stimulating the lips. 


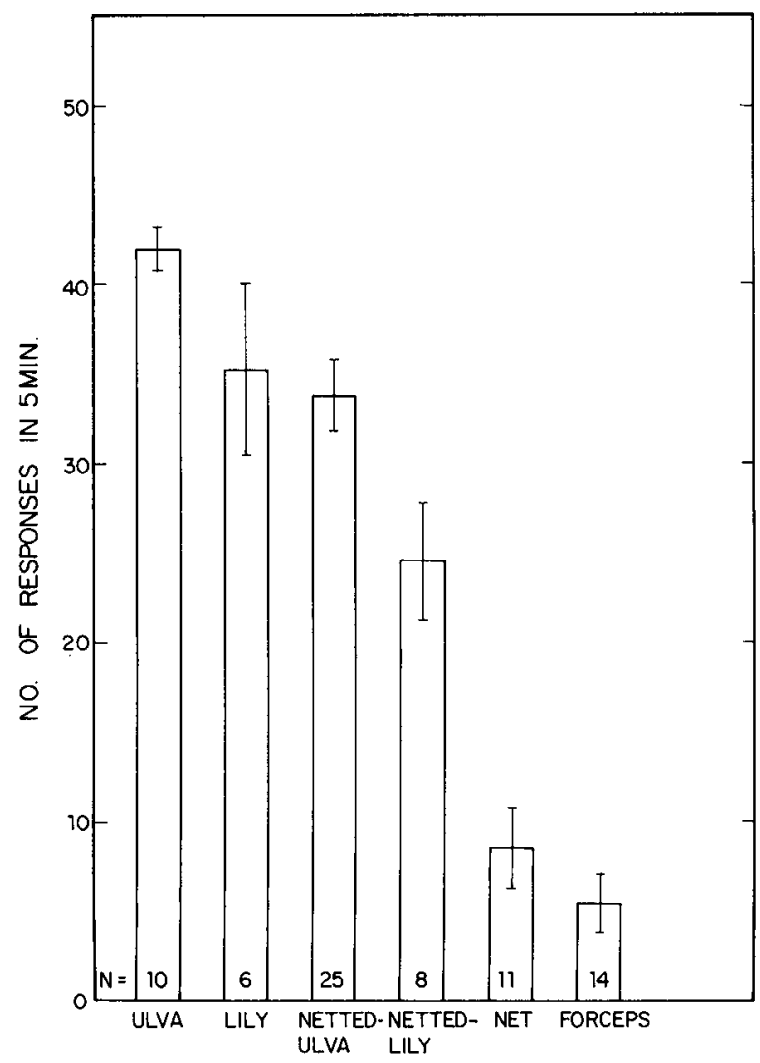

Figure 2. Number of feeding responses performed when stimulated for 5 min with Ulva, lily, netted Ulva, and netted lily; all these stimuli sustain feeding about equally well. Also shown are number of responses to non-food stimuli: net alone or touch of forceps to the lips. Number of animals in each group $(N)$ is indicated, as are SE. Data are from $A$. fasciata.
Edible netted food was prepared by packing a square of net $6 \mathrm{~cm}$ per side with as much $U l v a$ as it would hold. A hole was cut at the apex of the folded square to allow animals to pull food out of the net. The hole was constructed by opening the partitions between four adjacent holes through the net, so that the hole was $3 \mathrm{~mm}$ per side, large enough for A. oculifera to pull food out of the hole. As soon as animals succeeded in consuming all of the food in a net, they were immediately presented with a second net full of food.

\section{Results}

\section{Foods of different tastes and textures initiate feeding}

To alter their response to a specific food, Aplysia must have the ability to differentiate between foods; this has not been demonstrated. Aplysia use both chemical and tactile stimuli to recognize the presence of food (Rosen et al., 1982b), and they may also use these stimulus modalitics to tcll foods apart. To develop a paradigm in which discrimination depends on one modality, it was useful to find foods with similar mechanical properties but different taste, and foods with similar taste but different texture. Two smooth-textured plants were used: thalli of the seaweed $U$. lactuca and leaves of the lily $H$. fulva. The texture was changed by wrapping the plants in rough netting; Aplysia taste the food through holes in the net. Net alone could be used as a purely tactile stimulus with a texture identical to that of netted food.

Touching food and nonfood stimuli to the lips of Aplysia initiates a state of food arousal: As animals become aroused, response frequency increases from a rate close to zero to a steadystate response rate (Susswein et al., 1978). We touched the lips of quiescent animals with rough and smooth-textured $U l v a$ and lily and with nonfood tactile stimuli, and investigated whether the substances produced food arousal followed by sustained feeding. Stimuli were tonically maintained on the lips, except for a brief withdrawal when the Aplysia responded, in order to prevent entry of food into the mouth. Figure 1 shows that both smooth and net-enclosed foods induced food arousal. The initial
A. OCULIFERA

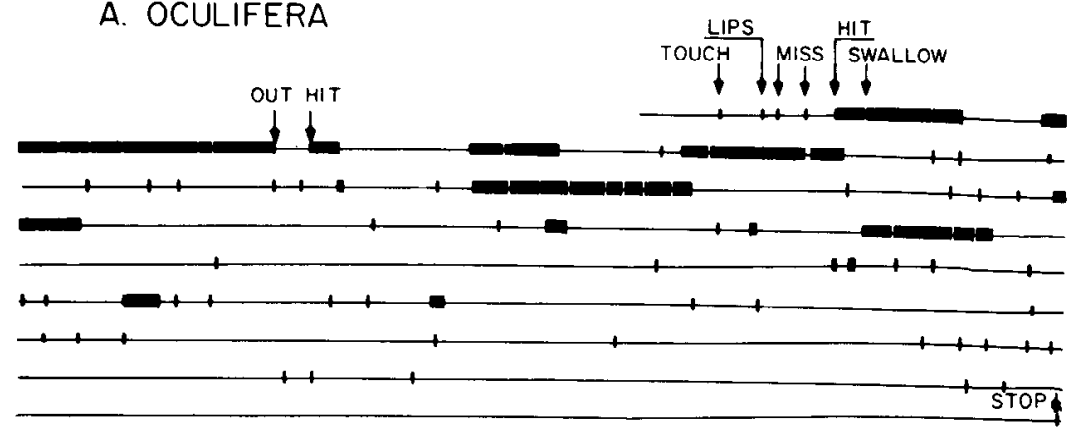

Figure 3. Continuous record from a pen recorder, showing response pattern during training in $A$. oculifera and $A$. fasciata. First event in both records (Touch) is touching food to the rhinophores. Animals respond by lifting the head, and food is then touched to the lips (Lips). Early responses are weak and are ineffective in leading to food entry into the mouth (Miss); subsequent responses lead to entry of food into the mouth (Hit). Period of time in which food remains in the mouth is indicated by a thickening of the line. During this period, swallowing responses occur, and these are indicated by a brief interruption of the thickened line (Swallow). Eventually, food leaves the buccal cavity $(O u t)$. It soon reenters, because lip stimulation is maintained. 


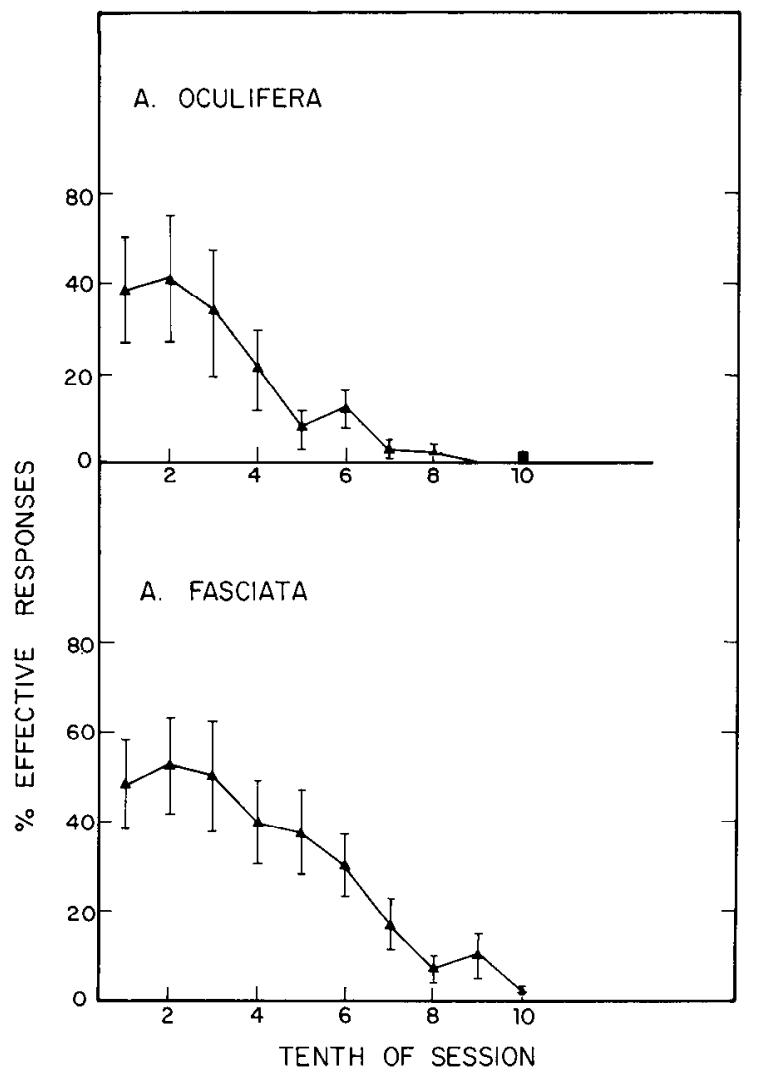

Figure 4. Percentage of effective feeding responses during training for $A$. oculifera $(n=6)$ and $A$. fasciata $(n=10)$ trained on inedible netted Ulva. The training session of each animal was divided into 10 equal time intervals, and the percentage of feeding responses leading to entry of food into the mouth was calculated for each tenth per animal. The means and SE were then calculated, and are shown here.

latencies to these stimuli were similar $(F=0.48, d f=3,43$; oneway analysis of variance). Purely tactile stimuli (net alone or touch of forceps) also initiated feeding but were less effective than were netted or non-netted foods.

To determine the relative efficacy of tactile stimuli and of rough and smooth foods in sustaining feeding, response rate was measured during $5 \mathrm{~min}$ of continuous stimulation of the lips after the first response. As above, food was withdrawn when the animal responded, preventing entry into the mouth. Figure 2 shows that both rough and smooth foods reliably sustained feeding responses about equally well $(F=0.47, d f=3,47$; one-way analysis of variance between the four groups). Tactile stimuli such as net alone or forceps sustained feeding at a much reduced level.

Data presented in Figures 1 and 2 are for $A$. fasciata. Responsivencss to netted Ulva $(n=10)$ and lily $(n=7)$, and nonnetted Ulva $(n=9)$ and lily $(n=8)$ was also determined in $A$. oculifera. This species also responded about equally well to all four foods.

\section{Response decrement to inedible food}

Net-enclosed and non-netted foods differ, in that the former is inedible. If food is not withdrawn, response to non-netted food leads to entry of food into the buccal cavity, and subsequent swallowing movements push food into the crop (Kupfermann, 1974). By contrast, netted foods are tough; consequently, swallowing responses are ineffective in pushing food into the gut. In this section, we report that ineffective attempts to push food into the gut, or stimuli arising from such attempts, act as negative reinforcers of feeding.

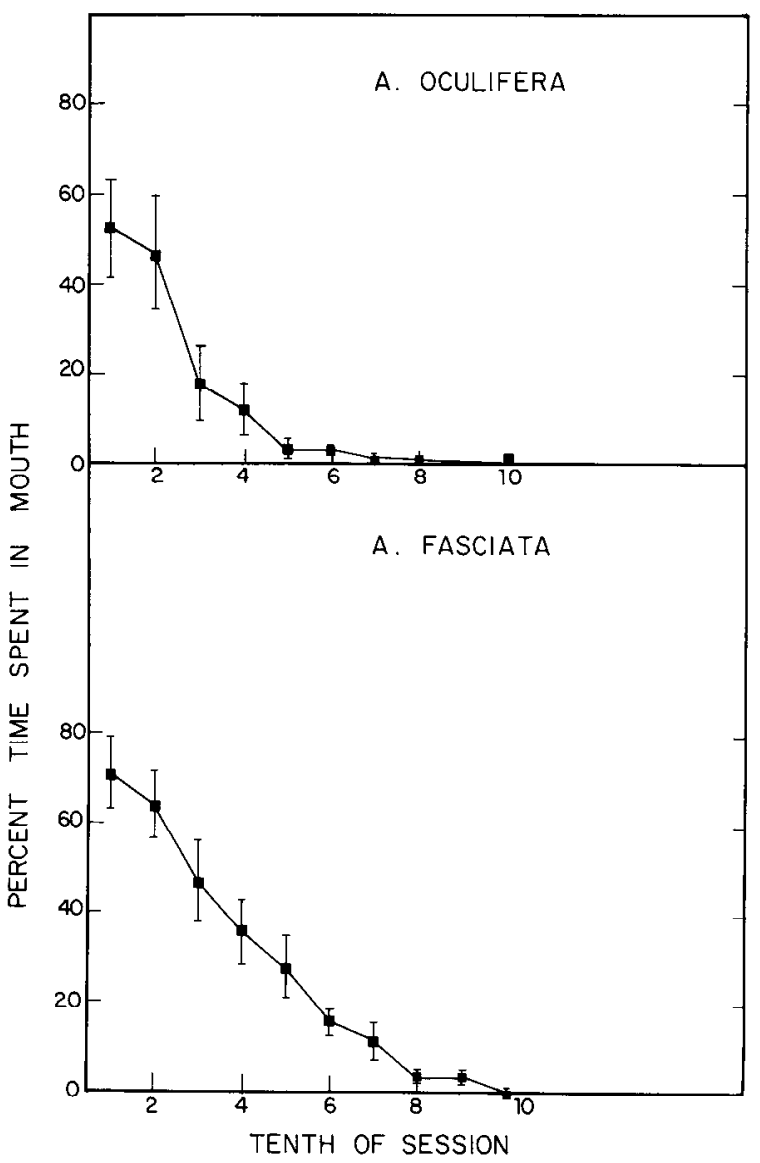

Figure 5. Percentage of time food was in the mouth during training, for $A$. oculifera $(n=6)$ and $A$. fasciata $(n=20)$. The training session of each animal was divided into 10 equal time intervals, and for each tenth per animal the percentage of the tenth that food was within the mouth was calculated. The means and SE were then determined, as shown.

\section{Parametric features of response decrement}

Feeding responses are first altered and then cease when paired with failed attempts to transport food from the buccal cavity to the crop. As above (Figs. 1 and 2), feeding in both $A$. fasciata and $A$. oculifera was initiated by netted Ulva and lily; however, food was not withdrawn when the animal responded, allowing the food to enter the buccal cavity and produce swallowing responses that were ineffective in pushing food into the crop.

Figure 3 shows pen-writer recordings made while training $A$. fasciata and $A$. oculifera on inedible netted foods. Events during training were observed visually, and their occurrence noted. The motor pattern during training was similar in both species, although time to criterion for $A$. oculifera was shorter (sce bclow, Fig. 9).

Training begins by touching food to the rhinophores. In response to this stimulus, the animal raises its head, and food is touched to the lips. After a variable latency, a feeding response, probably a bite, occurs. Initial bites are often ineffective in leading to food entry, reflecting a lack of complete food arousal (Susswein et al., 1978; Weiss et al., 1981). With subsequent, stronger bites, food enters the mouth and remains within the buccal cavity for an extended period of time. Swallows then occur that are unsuccessful in pushing food into the gut; the swallows are felt by the experimenter as an inward pull on the food. Eventually, food leaves the buccal cavity, usually because it is actively pushed out by the animal; the push can be felt by the experimenter, and probably represents a rejection response 


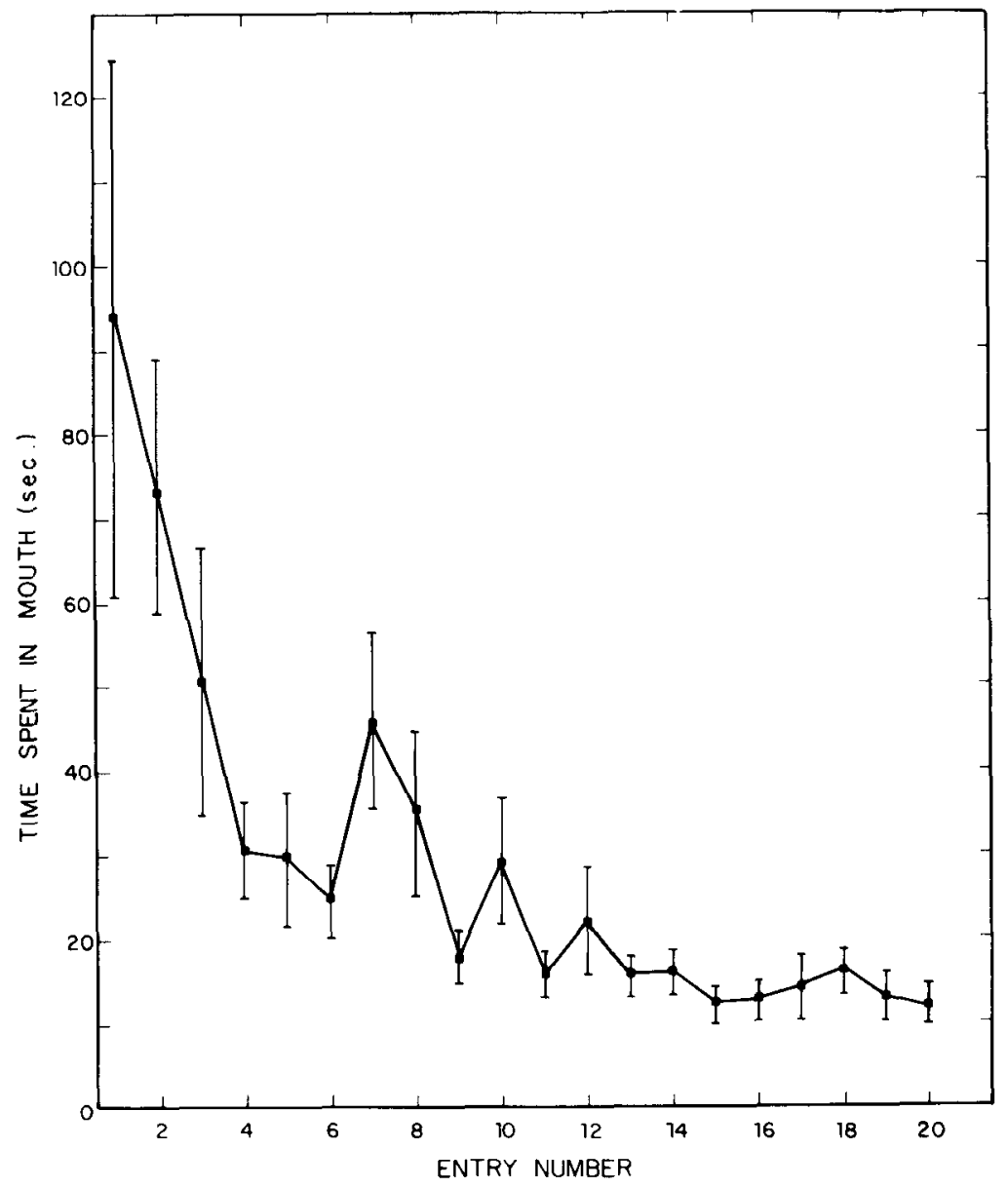

Figure 6. Time food was in the mouth as a function of entry number in a population of 20 A. fasciata. Mean and SE of time food was in the mouth for each of the first 20 successful feeding responses were calculated, as shown. Number of animals represented decreases with entry number, since some animals performed only a small number of effective responses.

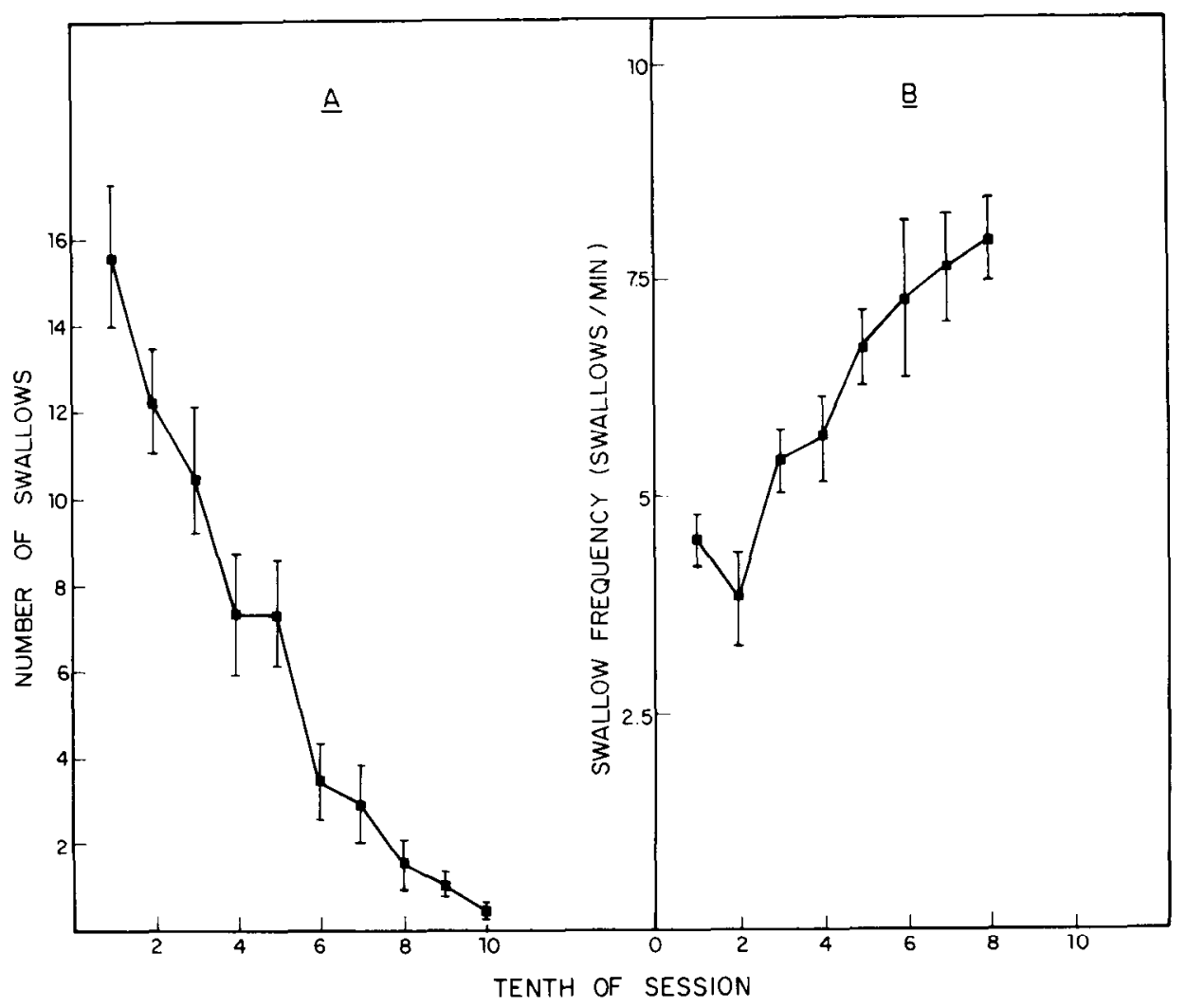

Figure 7. Swallow rate in a population of $20 \mathrm{~A}$. fasciata. $A$, Number of swallows occurring during each of 10 equal time periods from the start of training until criterion. $B$, Swallow frequency during each tenth of training sessions. Swallow frequency was calculated by measuring the period for all interswallow intervals occurring in a tenth; period was then converted to frequency per minute. 
Figure 8. Correlation between number of swallows and time food spent in the mouth after entry in a population of $20 \mathrm{~A}$. fasciata. Because of the large number of points at which five or less swallows occurred, it was not possible to show these individually. In all entries in which five or less swallows occurred, mean time spent in mouth is indicated by a point, and the range by a bar. All entries in which six or more swallows occurred are indicated individually. Least-mean-square regression line is shown.

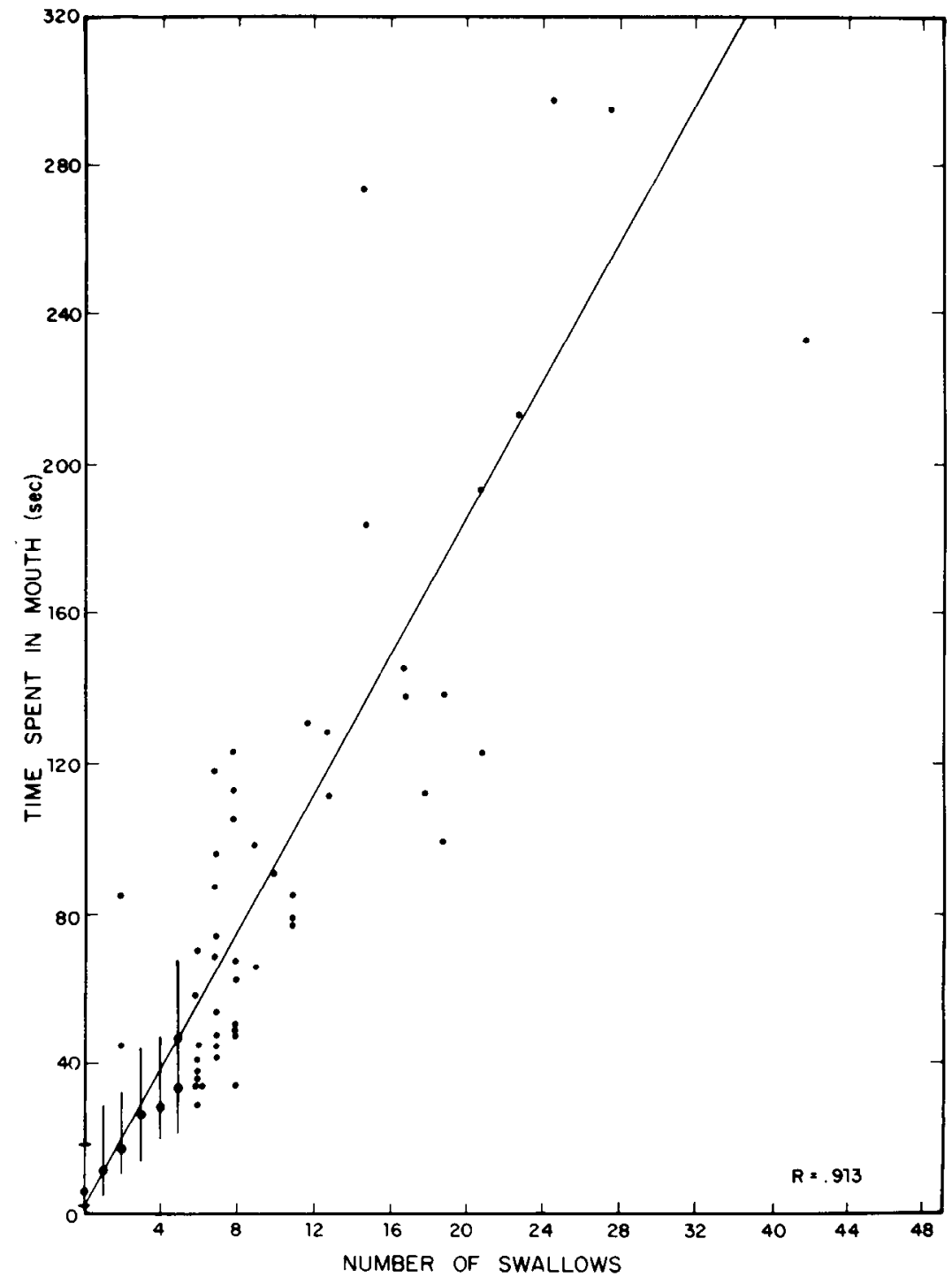

(Kupfermann, 1974). Because lip contact is maintained, successive bouts of feeding responses and attempted swallows occur. Figure 3 shows that as training progresses, proportionally fewer responses lead to food entering the buccal cavity. The nature of ineffective feeding responses cannot be determined at this level of analysis, but often the response seems to push food away from the mouth, suggesting that many ineffective feeding movements are rejection responses, rather than weak bites. Figure 3 also shows that when food enters the buccal cavity it is pushed out sooner. Eventually, the animals cease responding.

A number of parameters of feeding were measured to quantify the motor changes that occur during training. The parameters were (1) percentage of feeding responses that led to food entry; (2) percentage of time food remained in the buccal cavity; and (3) rate of swallows when food was in the buccal cavity. Training sessions were divided into 10 equal time periods, and the mean value for each parameter was calculated for each animal for each period; means and SE were then calculated for each period.

Effective versus ineffective feeding responses. Figure 4 shows the percentage of feeding responses that were effective in leading to food entry throughout training. From an initial value of $40-$ $50 \%$, virtually no feeding responses were effective by the end of training. The data indicate that training significantly decreased the likelihood that feeding responses would lead to food entry $(p<0.01, F=3.44, d f=9,50$ for $A$. oculifera; $p<0.01, F=$
4.68, $d f=9,90$ for $A$. fasciata; one-way analysis of variance). The change from effective to ineffective feeding responses was probably due to an increased likelihood of rejecting food, rather than of biting at it.

Time spent in buccal cavity. Figure 5 shows the percentage of time food remained in the buccal cavity throughout training. The initial value was $50-70 \%$; however, by the end of training, food spent virtually no time in the buccal cavity (for $A$. oculifera: $p<0.001, H^{\prime}=38.5, d f=9$; for $A$. fasciata: $p<0.001, H^{\prime}=$ $66.8, d f=9$; Kruskal-Wallis ranked "one-way analysis of variance").

It is possible that the change in time food remained in the buccal cavity was a consequence of fewer entries, but that once food entered the buccal cavity it remained there for the same period of time. To test this hypothesis, the time that food remained in the buccal cavity was examined for each of the first 20 food entries. Figure 6 shows this relationship. The data indicate that the likelihood increased that a given food entry would be brief as the animals were trained.

Rate of swallows. Figure 7 shows the occurrence of swallows throughout training in $A$. fasciata, using two measures: (1) number of swallows in each 10th of the session; and (2) the swallow frequency per 10 th, computed by directly measuring the time interval between swallows. No measures of swallow frequency are available for the last portion of training sessions, since no 


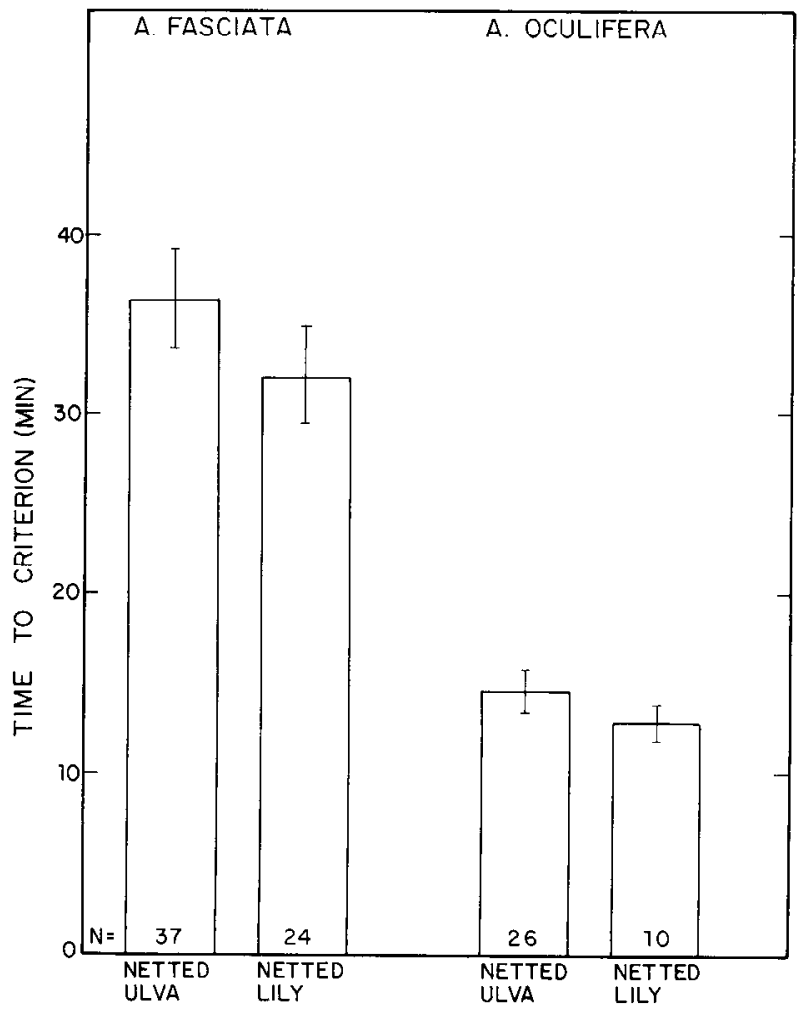

Figure 9. Time to reach criterion for cessation of feeding on training with inedible netted Ulva and lily in A. oculifera and A. fasciata. In A. fasciata, time to criterion varies in animals run at different times of the year (unpublished observation). Data are combined from animals run over a number of years during the entire season of animal availability. Number of animals in each group $(N)$ is indicated, as are SE.

interswallow intervals occurred. The data indicate that the number of swallows significantly decreased during training ( $p<$ $0.001, H^{\prime}=107.80, d f=9$; Kruskal-Wallis ranked "one-way analysis of variance"), while swallow frequency increased ( $p<$ $0.001, H^{\prime}=87.76, d f=7$; Kruskal-Wallis ranked "one-way analysis of variance"). In $A$. oculifera, no interswallow intervals were observed after the first $30 \%$ of the training session, precluding measurement of swallow frequency.

The data indicate that the decline in the number of swallows during training cannot be attributed to a slowing of the oscillator that sets the swallow frequency, since swallow frequency increased; rather, the number of swallows probably decreased because food does not enter the buccal cavity to elicit swallowing. Figure 8 shows the relationship between the time food remained in the buccal cavity following an effective feeding response and the number of swallows that occurred during that time. The close relationship between these parameters indicates that under our experimental conditions, occurrence of swallowing is largely a function of whether food is present in the buccal cavity to elicit swallowing.

Time to cease responding. Figure 9 shows the time needed for $A$. fasciata and $A$. oculifera to stop responding to netted Ulva and lily. Time to criterion (one response in a $3 \mathrm{~min}$ interval) was significantly longer in $A$. fasciata than in $A$. oculifera; no difference was found in time to criterion with netted Ulva and lily (between-species difference: $p<0.01, F=63.4, d f=1,93$; between-foods difference: $0.25>p>0.1, F=1.69, d f=1,93$; interaction: $F=0.07$; two-way analysis of variance).

\section{Memory of response decrement}

To test whether the animals retain memory of the training, we investigated whether time to criterion was shorter when animals were trained a second time. Twenty-four hours after training, animals were retraincd in a procedure identical to the first session. In a second group of animals, $48 \mathrm{hr}$ separated the training sessions. Experiments on animals with a $48 \mathrm{hr}$ intertraining interval were performed using a blind procedure: The experimenter was not informed whether a given training session was the first or second. Figure 10 shows that time to criterion on retraining was significantly shorter than time to criterion during the original training session (for $24 \mathrm{hr}$ retention: $p<0.002, t=$ $4.21, d f=12$; for $48 \mathrm{hr}$ retention: $p<0.05, t=2.72, d f=8$; two-tailed $t$ test for paired comparisons).

\section{Effects of lip stimulation}

To test whether the response change might have resulted from sensory adaptation or habituation of sensory pathways due to

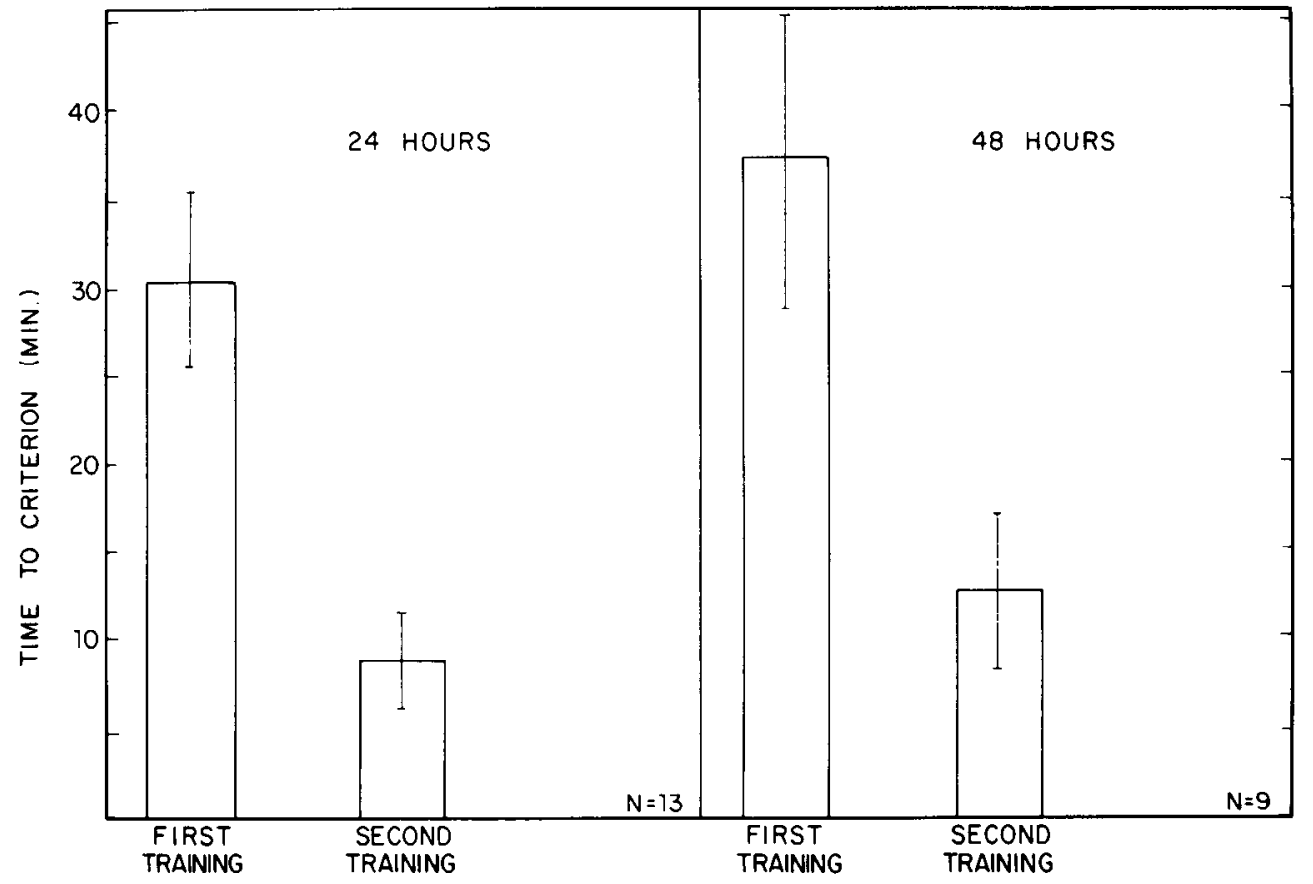

Figure 10. Memory of training, as measured by savings on retraining. At 24 or $48 \mathrm{hr}$ after training, animals were retrained in an identical procedure. Mean time to criterion and SE are shown for both training sessions. Data are from A. fasciata. 


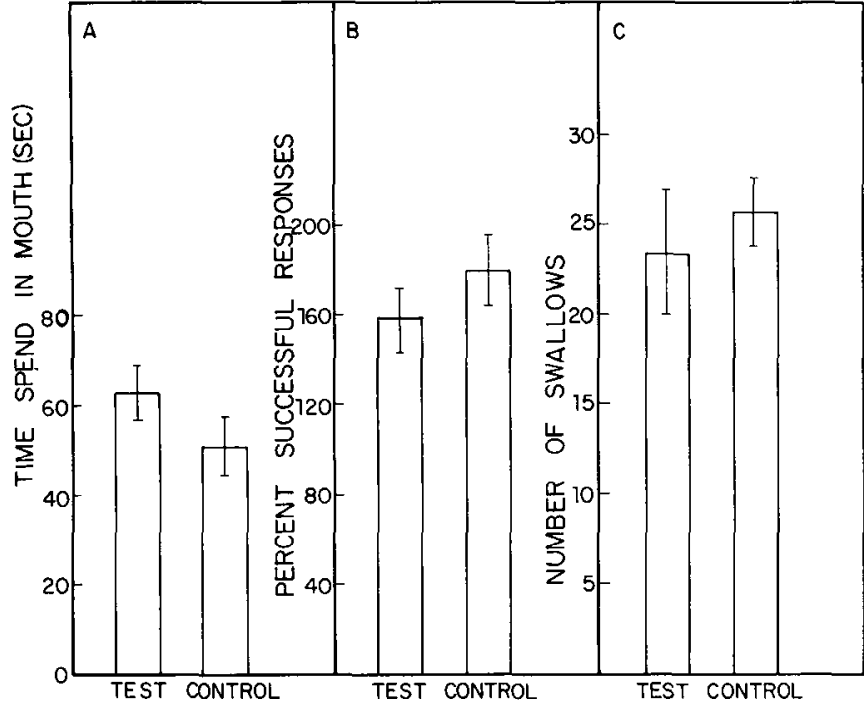

Figure 11. Effects of conditioning on arousal latency. Latency to respond to the first presentation of food is shown for the netted food used to train animals (Food \#l) and for the foods of alternate taste and texture that were touched to the lips after criterion for cessation of feeding was reached (Food \#2). Data are combined from all groups in which food of alternate taste or texture was presented to animals after learning. Number of animals run is indicated $(n)$, as are SE. Data are from $A$. fasciata.

continuous food stimulation of the lips, six $A$. fasciata were exposed to netted Ulva for $20 \mathrm{~min}$, which is two-thirds of the time to criterion for cessation of responses; food was withdrawn on response, preventing entry into the mouth. Immediately after, a second experimenter fed the animals inedible netted Ulva for $5 \mathrm{~min}$ in a procedure identical to that during training. Effective and ineffective feeding responses were noted, as were swallows, and duration of food retention in the mouth. As controls, six naive animals were run for $5 \mathrm{~min}$ in a blind procedure. Figure 11 shows that $20 \mathrm{~min}$ of preexposure to netted food produced no change in any of the parameters affected by training (percentage of effective feeding responses: $p>0.2, t=1.19$; time food spent in the mouth: $p>0.2, t=0.96$; number of swallows: $p>0.5, t=0.55$; two-tailed $t$ test, $d f=10$ for all measures).

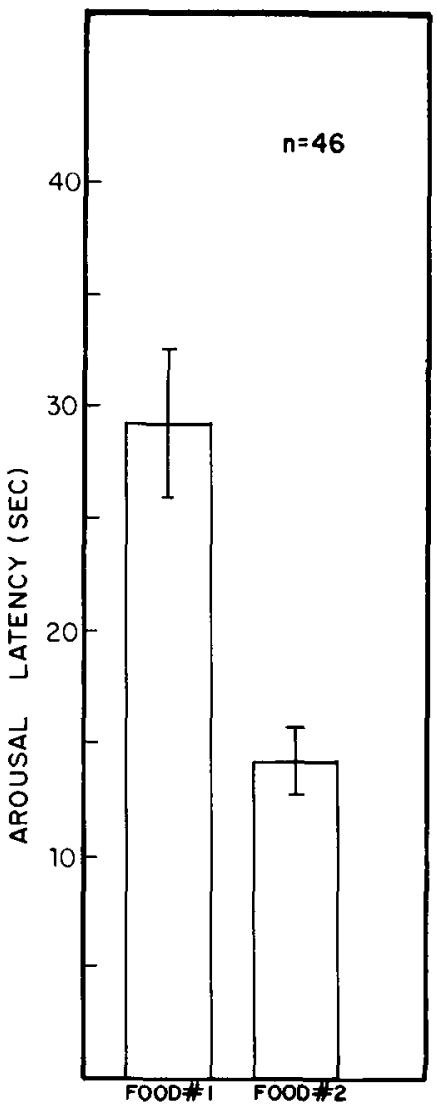

Figure 13. Potential effects of adaptation on feeding parameters. Comparison of three parameters of feeding during $5 \mathrm{~min}$ exposure to inedible netted Ulva in $6 \mathrm{~A}$. fasciata that had received $20 \mathrm{~min}$ of stimulation with netted Ulva on the lips that did not enter the mouth (Test) and in 6 naive animals (Control). $A$, Time spent in mouth; $B$, percentage of responses that were effective in leading to food entry; $C$, number of swallows performed. SE are shown.

\section{Specificity of response decrement to particular food}

The decrease in responsiveness to inedible netted food could have resulted from motor fatigue or nonspecific inhibition. To rule out these possibilities, we demonstrated that the response decrement was specific. The availability of foods of differing

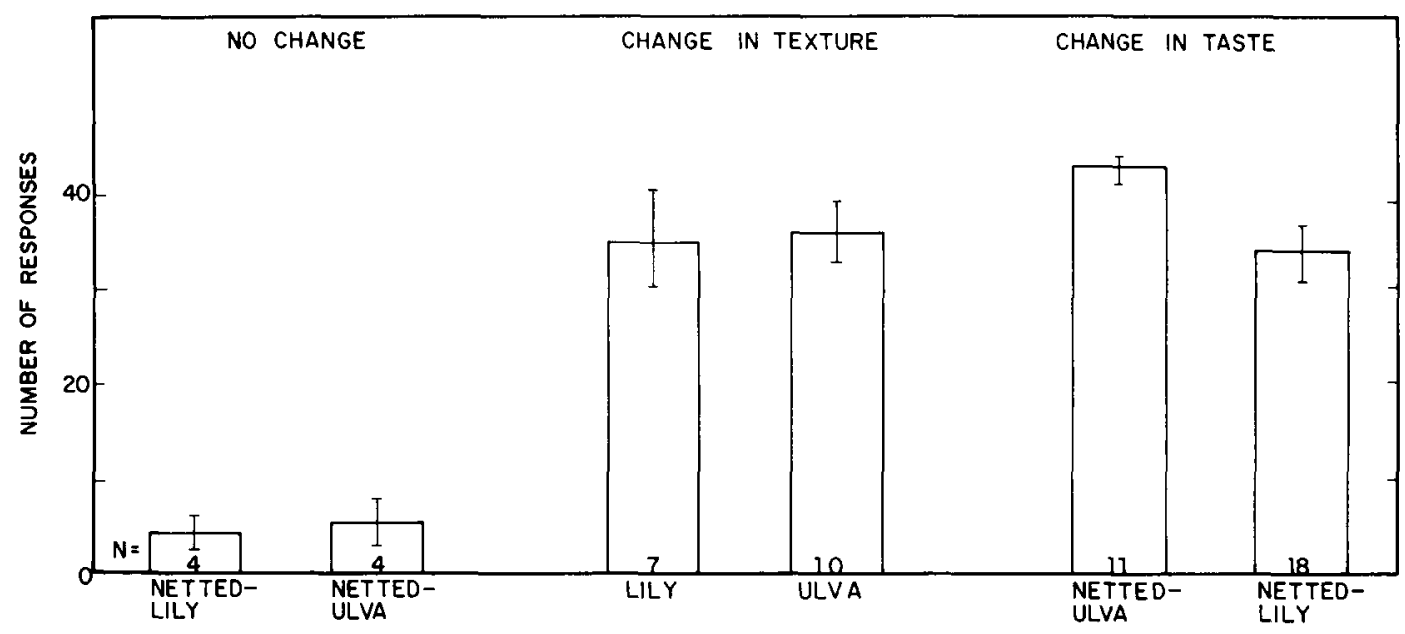

Figure 12. Specificity of training, as measured by responsiveness to alternate foods. After criterion for training with inedible netted Ulva or lily, response rate to $5 \mathrm{~min}$ of stimulation with either the same food as during training (netted Ulva or lily); food of alternate texture (un-netted Ulva or lily); food of alternate taste (reversing netted $U l v a$ and netted lily). The food to which response rate was measured after training is indicated (Netted Ulva, Netted lily, Ulva, or Lily). Number of animals in each group is shown $(N)$, as are SE. Data are from $A$. fasciata. 


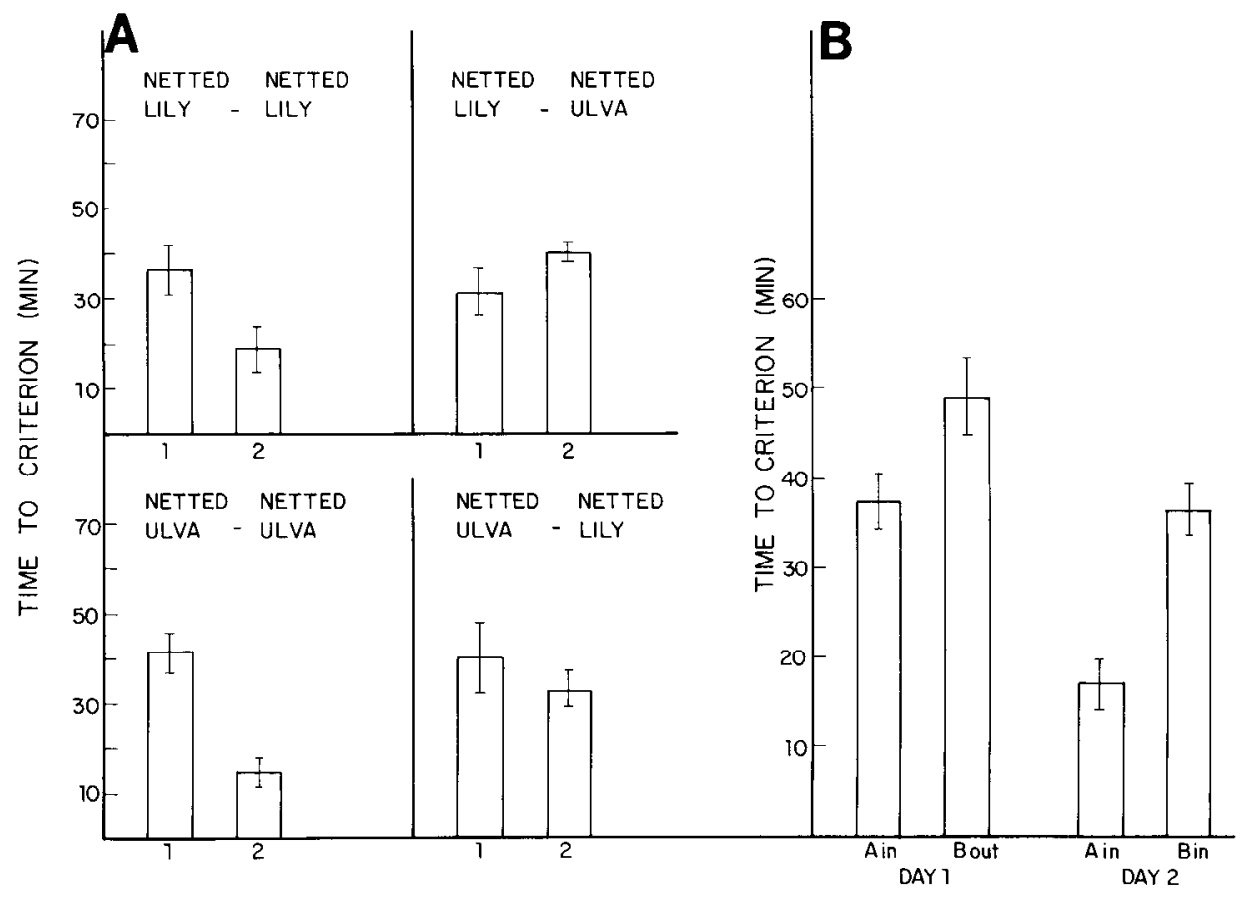

Figure 14. Specificity to pairing. On Day 1 , feeding responses were paired with one of two netted foods (netted Ulva or lily, 10 each) but were explicitly unpaired with the other food. Twentyfour hours later, half the animals (five trained with Ulva, five with lily) were retrained with paired foods, while the other half were retrained with unpaired foods. $A$, lime to criterion for each of the two training sessions on the two successive days. Data are shown separately for all four treatment groups. $B$, Pooled data from all four groups, showing time to criterion on Day 1 for Treatment $1\left(A_{i n}\right.$, a normal training procedure with inedible netted food) and time to criterion on Day 1 for Treatment 2 $\left(B_{\text {our }}\right.$, stimulation of the external lips with an alternate food, producing feeding responses that were not followed by swallows). On Day 2, all animals received a normal training procedure, but in half the animals this was on the food presented on Day 1 in Treatment $1\left(A_{i n}\right)$, and in the other half on the food presented on Day 1 in Treatment $2\left(B_{i n}\right)$. $\mathrm{SE}$ are shown. Data are from $A$. fasciata. tastes and textures allowed us to determine whether Aplysia can differentiate between foods on the basis of either taste or texture. After cessation of responses to inedible netted Ulva or lily, we compared the response rate to the original food with that to foods of alternate taste or texture. Taste was changed by substituting netted Ulva for netted lily and vice versa. Texture was changed by substituting smooth Ulva for net-enclosed Ulva, and smooth lily for net-enclosed lily. One minute after criterion, the lips were stimulated with either the original food or with alternate food for $5 \mathrm{~min}$, starting from the first response. Food was briefly withdrawn at the response, preventing entry into the mouth. The experiment was performed on $A$. fasciata.

Figure 12 shows that the response rate to alternate foods was higher than that to the original food (pooled data from all experiments in which alternate versus the same food was presented: $p<0.002, t=7.39, d f=52$; two-tailed $t$ test). No difference was found in response to Ulva, lily, netted Ulva, or netted lily when these served as the alternate taste or texture ( $F=0.41, d f=3,42$; one-way analysis of variance). These data indicate that the response change is specific to both taste and texture; altering either restores feeding.

On first exposure to food, quiescent animals must become aroused before responding reliably to food (see Fig. 1). Following cessation of feeding, we found that responses to alternate foods differed from those of naive animals when initially exposed to the first food. Figure 13 shows the latency in responding to the first touch of food at the start of training and the initial latency in responding to alternate foods after training. Initial latency to alternate foods was significantly shorter than that of the same animals when first exposed to food ( $p<0.001, t=3.97, d f=$ 46; paired $t$ test). This indicates that the state of food arousal due to the first food was maintained, despite cessation of responsiveness to the food.

\section{Specificity to pairing with reinforcing stimuli}

Response decrement could have been due to the pairing of feeding responses produced by a specific food, with reinforcement arising from failed attempts to transfer food from the buccal cavity to the gut; alternatively, effects could have been due to factors independent of pairing. Demonstrating that a response change depends on pairing requires assessing the potential effects of unpaired stimuli (Reynolds, 1975). In most studies, effects of independent presentation of the reinforcing stimulus are determined. In our training paradigm the negative reinforcer cannot be presented independently, since animals must first respond to food before they can fail to transport it to the gut. To overcome this problem, within a given training session animals were exposed to two foods, but negative reinforcement was paired to feeding in response to only one of them; with respect to feeding in response to the other food, reinforcement was explicitly unpaired. We took advantage of the findings that learned behavioral change is specific and that savings on retraining are evident for $24 \mathrm{hr}$, and therefore examined whether savings are contingent on pairing. If behavioral change is due to pairing, one would predict that savings on retraining would be exhibited only with the food signaling negative reinforcement in the original training. Since the experiment was easily performed using blind procedures, it could also provide blind confirmation of specificity to a particular food and memory retention for $24 \mathrm{hr}$.

We first paired feeding responses on netted Ulva or lily with failure to transfer food into the gut in a procedure identical to that described above (Treatment 1). One minute after criterion for cessation of feeding, netted food of alternate taste was touched to the lips and feeding responses occurred; however, food was withdrawn at the fccding response to prevent entry of food into the buccal cavity and subsequent swallowing movements (Treatment 2). The food in Treatment 1 signals that feeding is followed by failure to transfer food to the crop; the food in Treatment 2 signals that feeding responses and failure to transport food are temporally unrelated, since failure occurred only before exposure to this food. Treatment 2 continued until animals ceased to respond to the food, presumably due to sensory adaptation or habituation that is unrelated to learning (Schwarz and Susswein, 1986). In 18 of 20 cases, exposure to the food in Treatment 2 was longer than in Treatment 1 . Twenty-four hours later, animals were retrained with either the netted food from Treatment 1 or Treatment 2 . In this procedure, feeding responses were followed by entry of food into the buccal cavity and failed food transport. All procedures were done blind: At no time 
Figure 15. Parametric features of feeding in the first 5 min of training on Day 1 , and the same parameters during the first 5 min of training on Day 2, in animals trained in a blind procedure on identical foods during the $2 \mathrm{~d}$. Parametric features shown are $A$, percentage of effective feeding responses; $B$, time spent in mouth; $C$, number of swallows. SE are shown.

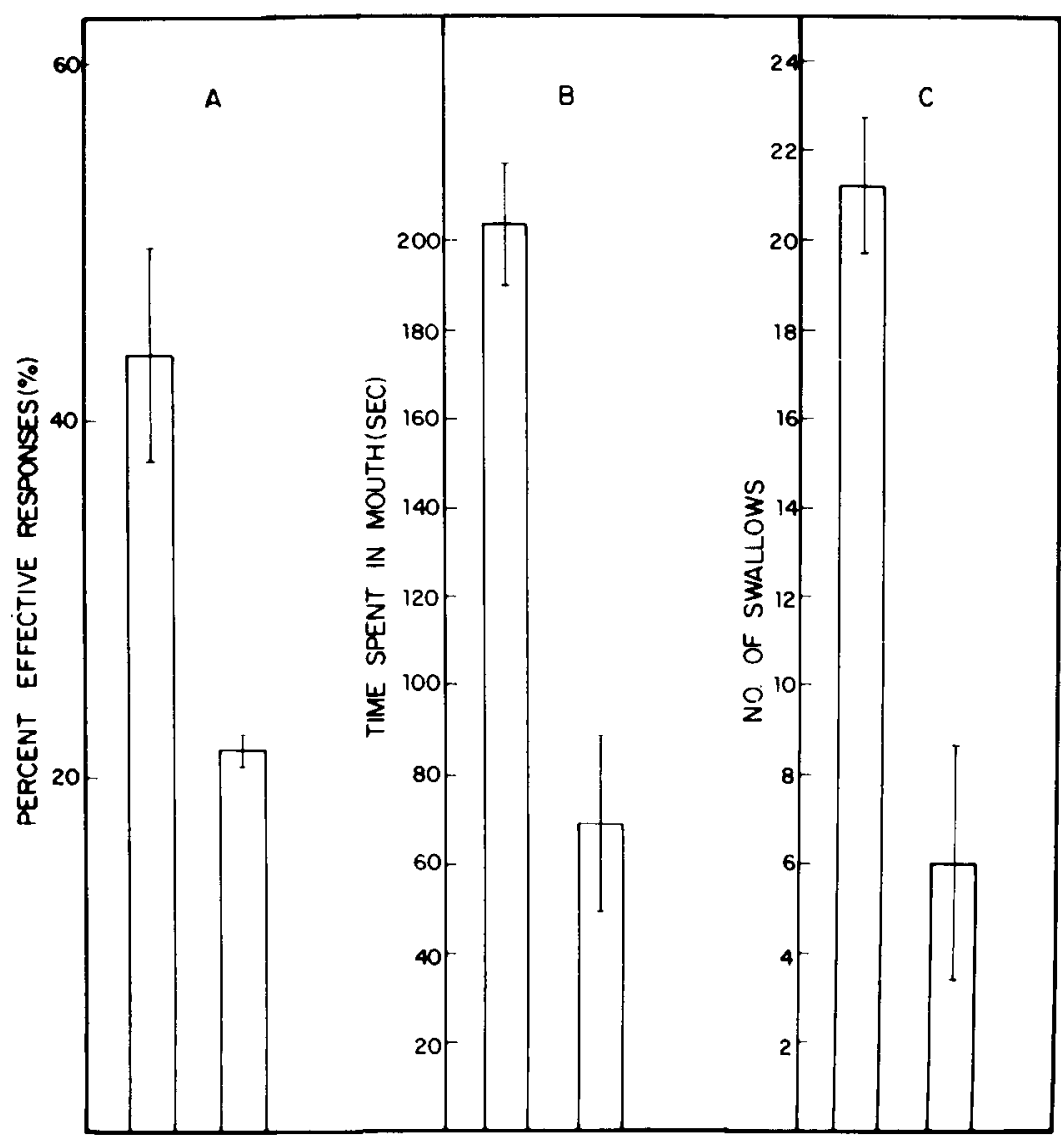

during the experiment was the experimenter aware of the nature of the foods presented (netted Ulva and lily are indistinguishable in appearance). The experiment was performed on $A$. fasciata.

Figure 14 shows that savings in time to criterion were evident on Day 2 only in response to foods in which feeding responses and failed transport were paired on Day 1 (pooled data from all animals in which training was identical on the $2 \mathrm{~d}: p<0.025$, $t=2.54, d f=9$; two-tailed $t$ test for paired comparisons). Time to criterion was not shorter on Day 2 with foods that had previously signaled that feeding responscs and failed transport are unrelated (pooled data from all animals in which training was on different foods on the $2 \mathrm{~d}: p>0.8, t=0.01, d f=9$; twotailed $t$ test for paired comparisons). Since all animals received equal food stimuli to the lips, performed feeding responses to both foods, and also failcd in attempts to transport food from the buccal cavity to the gut, this experiment effectively rules out all effects not dependent on pairing or a combination of such effects. In addition to demonstrating specificity to pairing, the experiment also provides blind confirmation of specificity to a particular food and of $24 \mathrm{hr}$ retention of learning.

This experiment also allowed us to examine whether changes in the pattern of feeding movements in the course of learning were due to pairing. As quantitative measures of motor pattern, three parameters were examined during the first 5 min of training on Day 2; these were compared with the same parameters on the previous day. Parameters examined were (1) percentage of effective feeding responses, (2) time food spent in the buccal cavity, and (3) number of swallows. Figure 15 shows that all three parameters changed on Day 2, when animals were given food that had been paired with negative reinforcement on Day 1 (percentage of effective responses: $p<0.05, t=2.21, d f=28$; time spent in mouth: $p<0.002, t=4.97, d f=28$; number of swallows: $p<0.002, t=4.54, d f=28$; Dunnett's test for comparing a number of treatments with a single control). None of the parameters was affected when animals were given food that had been unpaired with negative reinforcement on Day 1 (percentage effective responses: $t=0.51, d f=28$; time spent in mouth: $t=1.22, d f=28$; number of swallows: $t=0.45, d f=$ 28; Dunnett's test). These data indicate that changes in motor patterning are also a consequence of pairing.

\section{Response increment to edible foods}

If failed transport to the gut serves as a negative reinforcer when paired with feeding, we reasoned that successful food transport might act as a positive reinforcer. To test this possibility, $A$. oculifera were fed netted Ulva that had been made edible by cutting a hole in the net through which animals were able to pull the food. Biting responses led to entry of the netted food into the buccal cavity, and swallowing responses succeeded in transferring the food into the crop, through the hole. Stimulation was continued, until animals ceased to respond.

Figure $16 \mathrm{~A}$ shows a training session on edible netted Ulva. In addition to being much longer than training on inedible food, the pattern was altered: Throughout training, many responses were effective in leading to food entry, and once food entered the buccal cavity, it remained there for substantial periods of time.

To quantify differences in behavior in response to edible and inedible food, we examined a number of feeding parameters. Figure $17 \mathrm{~A}$ shows that when animals were fed Ulva in a net with a hole, time to criterion was more than twice that with inedible netted Ulva. Figure 18 shows that during the second half of training sessions, when motor effects due to training are most pronounced, significantly more feeding responses lead to food entry with edible food than with inedible food $(p<0.01$, $t=2.86, d f=20$; two-tailed $t$ test). During the second half of training, the percent time that food remained in the buccal cavity 


\section{A FIRST SESSION}

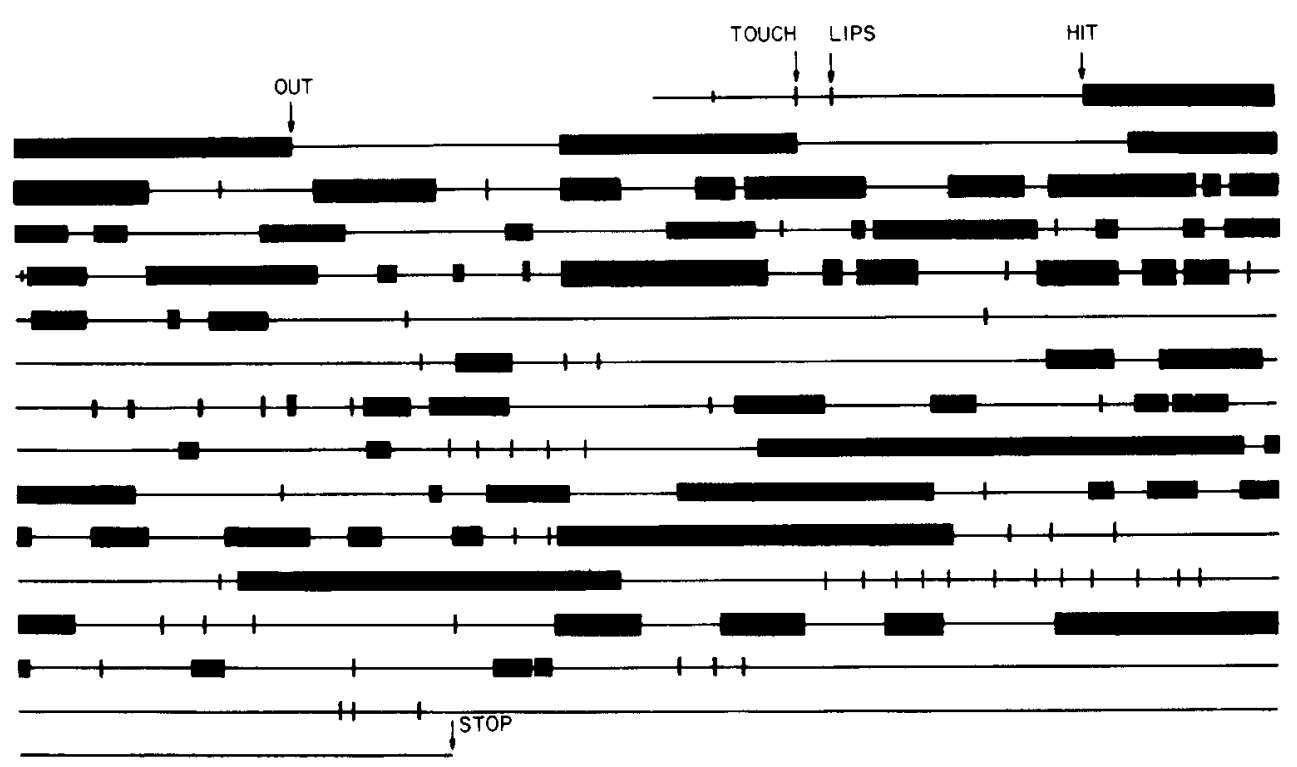

B SECOND SESSION

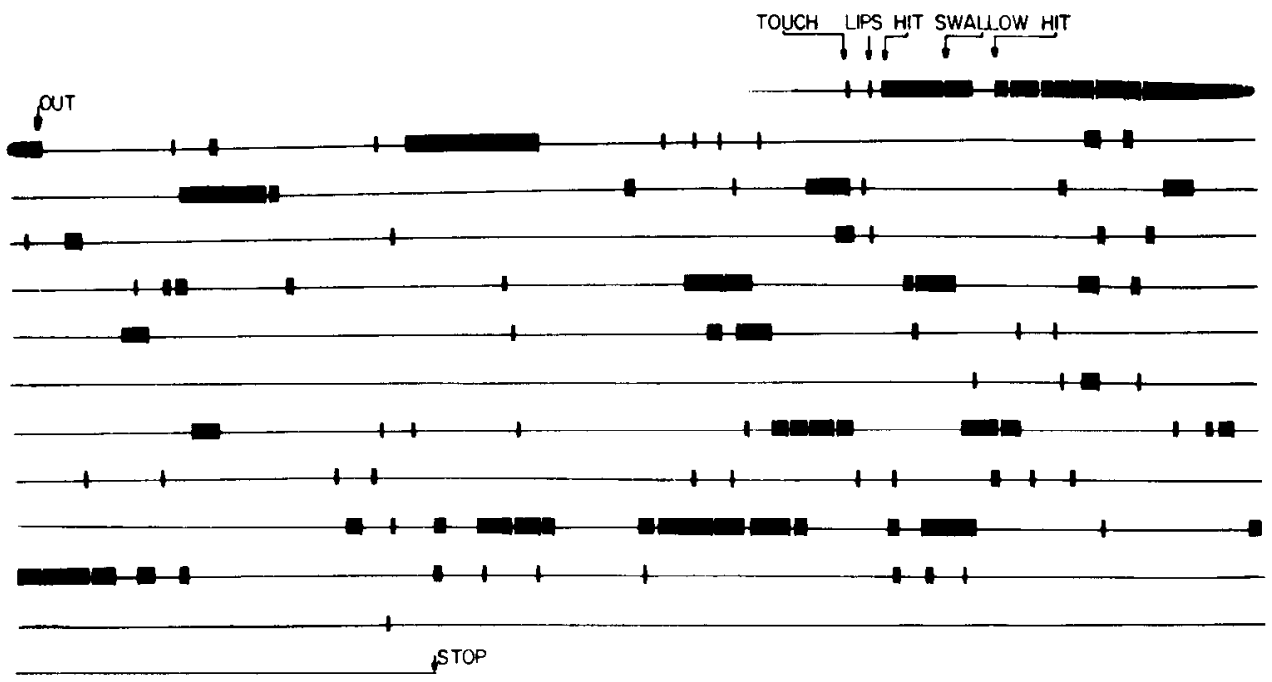

$\longmapsto 6 \mathrm{SEC}$
Figure 16. Continuous record from a pen recorder showing the response pattern during training on netted Ulva with a hole in the net, through which $A$. oculifera were able to pull out food. $A$, Original session on edible netted $C / l v a$. In this series of experiments, swallows were not noted. $B$, Three days later, the animal was retrained on inedible Ulva. Symbols used to mark each type of event are indicated in the first two lines of each record (see legend to Fig. 3). was also higher on training with edible netted food $(p<0.002$, $t=4.34, d f=20 ;$ two-tailed $t$ test). These data suggest that successful food transport might act as a positive reinforcer, and pairing successful food transport with feeding responses could teach animals that a specific food is edible.

If animals learn that netted food is edible, subsequent responses to the food should be more effective than responses of naive animals to the same food. We tested this possibility by observing the response to netted Ulva without a hole $3 \mathrm{~d}$ after the original training on edible netted Ulva. In the sccond session, netted food entered the buccal cavity but could not be swallowed. As controls, we observed the response of naive animals to inedible netted $U l v a$ and that of animals trained with inedible netted Ulva $3 \mathrm{~d}$ earlier. The experiment was performed using a blind procedure.

Figure $16 B$ shows the results of a training session on inedible netted Ulva, $3 \mathrm{~d}$ after training with edible netted $U l v a$. In addition to being longer than training in naive animals, motor pattern was different: Throughout training, relatively more feed- ing responses led to entry of food into the buccal cavity; also, food remained within the buccal cavity longer.

To quantify the changes in motor patterning, the percentage of feeding responses that were effective in leading to food entry and the percentage of time food spent in the buccal cavity were measured during the first $5 \mathrm{~min}$ of exposure to inedible netted food. Figure 19 demonstrates that in animals previously taught that the food was edible, significantly more feeding responses were effective $(p<0.02, d f=20$; two-tailed $t$ test) and significantly more time was spent in the mouth $(p<0.05, t=2.42$, $d f=20$; two-tailed $t$ test).

Figure $17 B$ shows that in animals previously trained with edible netted food, time to criterion was significantly longer than in naive controls ( $p<0.05, t=2.55, d f=15$; two-tailed $t$ test). Time to criterion was also increased comparcd with animals that had previously experienced failed swallowing. These data indicate that training on edible netted food impaired subsequent learning that the food is inedible.

It is possible that successful food consumption of netted food 


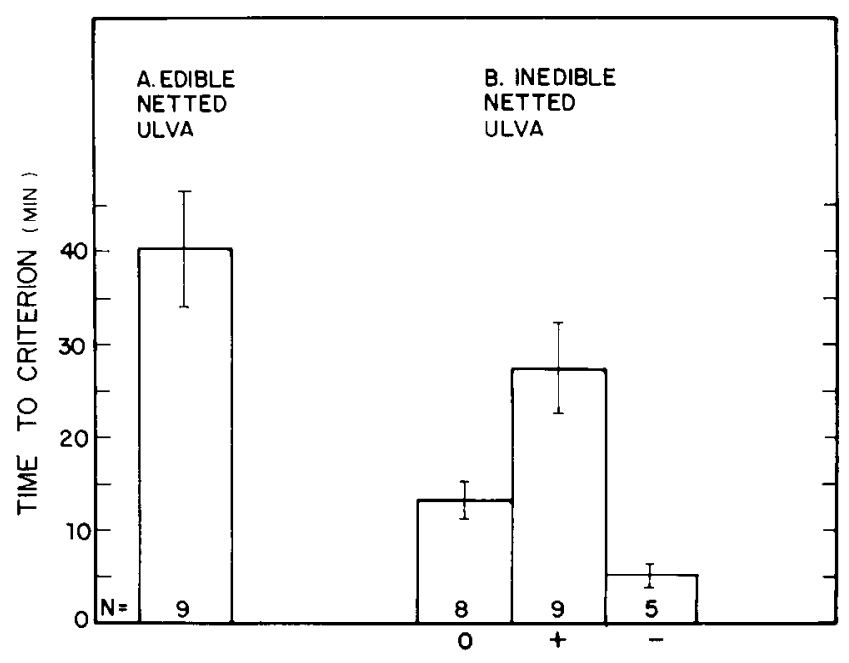

Figure 17. A, Time to nonresponsiveness to edible netted food. $B$, Three days later, the animals were run a second time with netted Ulva without a hole, making the food inedible. Feeding responses led to failed swallowing. This group is marked $(+)$, noting the fact that previous experience was positive reinforcement. As controls, time to stop responding is shown in naive animals $(0)$ and in animals that had been trained on netted food with no hole $3 \mathrm{~d}$ earlier (-). SE are shown. The threc groups were run blind. The experiment was performed on $A$. oculifera. The number of individuals in each group is shown $(N)$, as are SE.

led to increased responsiveness to the food and also impaired subsequent learning that the food is inedible as a result of previous exposure to the netted food and subsequent feeding movements, independently of whether successful food transport occurred; another possibility is that impairment was due to successful food transport into the crop per se, independently of pairing with feeding responses. To test these possibilities, $3 \mathrm{~d}$ before training with inedible netted $U l v a$, a group of animals was exposed to netted Ulva that was withdrawn at the response, preventing entry and subsequent swallowing. Exposure to food was maintained until animals ceased responding (Schwarz and Susswein, 1986). In a second group, $3 \mathrm{~d}$ before training with inedible netted $U l v a$, animals were fed a quantity of $U l v a$ matched to that eaten in experiments when animals succeeded in eating through the hole. Figure 20 shows that neither of these procedures affected subsequent learning to stop responding to inedible netted Ulva. The data indicate that impairment of subsequent learning that netted food is inedible was due to pairing of feeding responses with successful consumption of food.

\section{Discussion}

The data presented here indicate that feeding behavior in Aplysia is modified in a number of ways when followed by stimuli arising from failure to transport food from the buccal cavity into the gut. Sensory adaptation resulting from exposure to food, motor fatigue from performance of feeding responses, and nonspecific inhibition cannot explain the behavioral changes:

1. Sensory adaptation or habituation due to food exposure occurs but differs in numerous features from those demonstrated here (Schwarz and Susswein, 1986; M. Schwarz et al., unpublished observations).

2. The response decrement cannot be due to motor fatigue, since it is specific to food with a particular taste and texture.

3. Nonspecific effects of failure to transport food cannot explain the behavioral change, since when failure to transport food is unpaired with feeding, animals subsequently behave like naive animals.

Stimuli arising from successful food consumption seem to

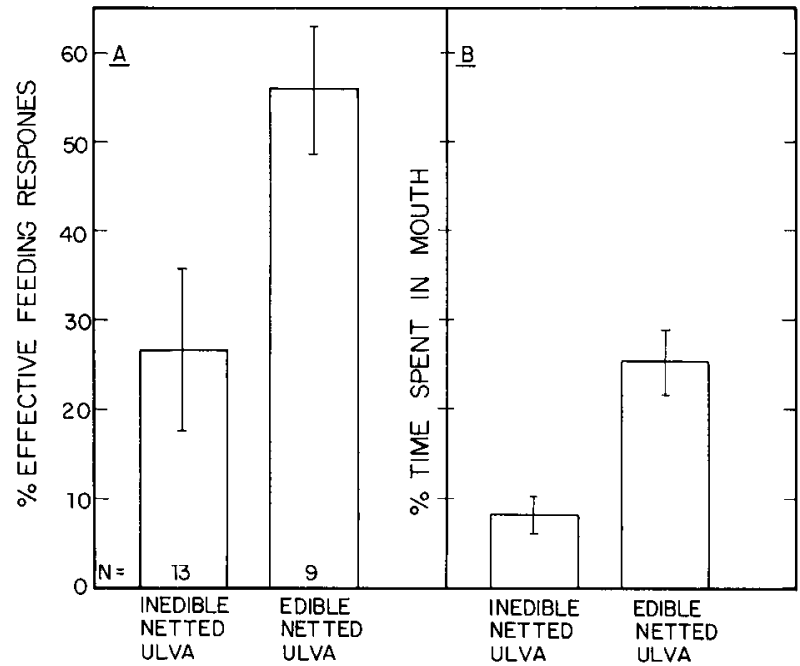

Figure 18. A, Percentage effective feeding responses during the second half of training, when animals were trained with edible and inedible netted Ulva. B, Percentage of time that food was in the mouth during the second half of training sessions, when animals were trained with edible and inedible netted $U / v a$. SE are shown. Data are from $A$. oculifera.

modulate feeding by producing effects that are opposite those arising from failed swallowing.

Modification of feeding behavior is due to an associative process. Animals learn that feeding responses to inedible food lead to failure to consume the food, while feeding responses to edible food lead to successful food consumption. Failure to consume food after it enters the buccal cavity seems to act as a negative reinforcer, and decreases the likelihood that events paired with it will recur; success in consuming food seems to act as a positive reinforcer.

The question arises as to the nature of the learning process. Operationally, associative learning phenomena are usually classified as being one of two types. In one, a neutral stimulus is paired with a reinforcing stimulus, and animals learn the association between the stimuli; this learning is variously termed Pavlovian (Rescorla and Solomon, 1967), classical (Mackintosh, 1973), respondent (Reynolds, 1975), type I (Konorski, 1967), or type S (Lorenz, 1982). In the other, the action of an animal is paired with reinforcement; this learning is variously termed Thorndikian (Rescorla and Solomon, 1967), instrumental (Mackintosh, 1973), operant (Reynolds, 1975), type II (Konorski, 1967), or type R (Lorenz, 1982). Numerous experiments have attempted to determine whether unique or common mechanisms underlie the two types of learning (Rescorla and Solomon, 1967), or whether either of the learning processes can be observed uncontaminated by the other (Mackintosh, 1973). To date, we have not addressed ourselves to determining conclusively the nature of our learning task in Aplysia. The paradigm has clear affinities to both types of learning, but on a procedural level, it seems to resemble instrumental learning more closely, in that reinforcement occurs only after animals respond.

A distinction is often made about the nature of behaviors affected by the two types of learning. Operant conditioning affects operant behaviors, which are distinguished from respondent behaviors by not being tied to a specific eliciting stimulus: While rate of occurrence of a respondent is a function of that of the stimulus eliciting it, operants are emitted spontaneously, at a rate set by the animal (Reynolds, 1975). Feeding in Aplysia has many features in common with both operant and respondent behaviors in higher animals, but seems to more closely resemble operant behaviors. Under laboratory conditions in which Aply- 


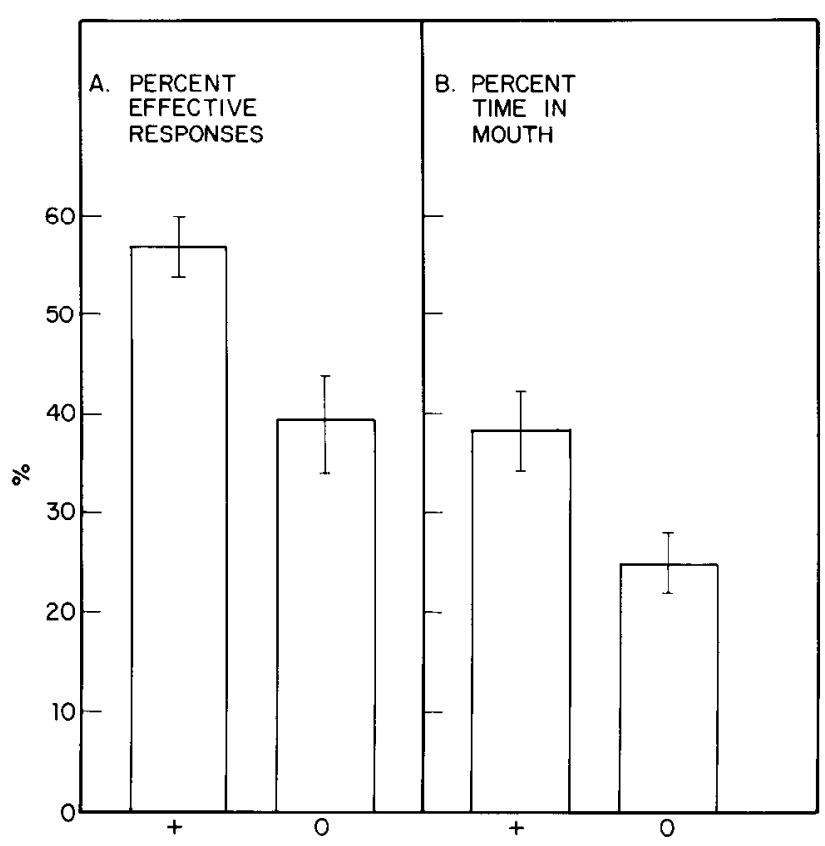

Figure 19. A, Percentage of effective feeding responses. $B$, Percentage of time that food was in the mouth. Both measures are from the first 5 min of training in animals that had previously trained with edible netted Ulva (+) or naive controls (0). SE are shown. Data are from $A$. oculifera.

sia are deprived from food, feeding responses can be elicited reliably by briefly touching food to the lips. The rate of feeding is identical to rate at which the lips are touched, and the behavior is respondent. However, under field conditions, food is always available, while feeding occurs only intermittently (Kupfermann and Carew, 1974; Susswein et al., 1983, 1984b). Feeding responses also occur spontaneously, as well as in response to nonfood stimuli (Kupfermann, 1974). Although food is certainly not a neutral stimulus with respect to feeding behavior, the behavior is only loosely tied to presentation of food. In the present experiments, food was available throughout the experiment, but internal mechanisms determined the animals' response.

Our learning paradigm most closely corresponds to what Lorenz (1982) has termed conditioned appetitive and conditioned aversive behavior. In this type of learning, an animal learns by feedback from performing a behavior about the environmental situations that are appropriate for the behavior. Lorenz (1982) provides a prototype for this learning: A dog learns by feedback to bury food remnants outdoors, rather than on the parquet floor of the dining room. Lorenz (1982) distinguishes learning by feedback about the environment from true operant conditioning, in which the nature of the behavior itself is changed.

Learning that food is inedible has clear affinities with the foodavoidance learning that has been shown in other gastropods (Mpitsos and Collins, 1975; Sahley et al., 1981a, b); however, the fact that Aplysia also learn that food is edible indicates that the phenomenon is more complex.

Our data indicate that Aplysia can distinguish between different foods on the basis of differences in both chemical and mechanical stimuli to the lips, since learning is specific to both the mechanical properties and the taste of food. We cannot eliminate the possibility that changing the mechanical properties also changes the taste: The barricr of the net may decrease the concentration of food substances acting on lip chemoreceptors. Nevertheless, the data suggest the involvement of pathways receiving convergent input from receptors responding to different modalities. Networks involved in feature extraction and

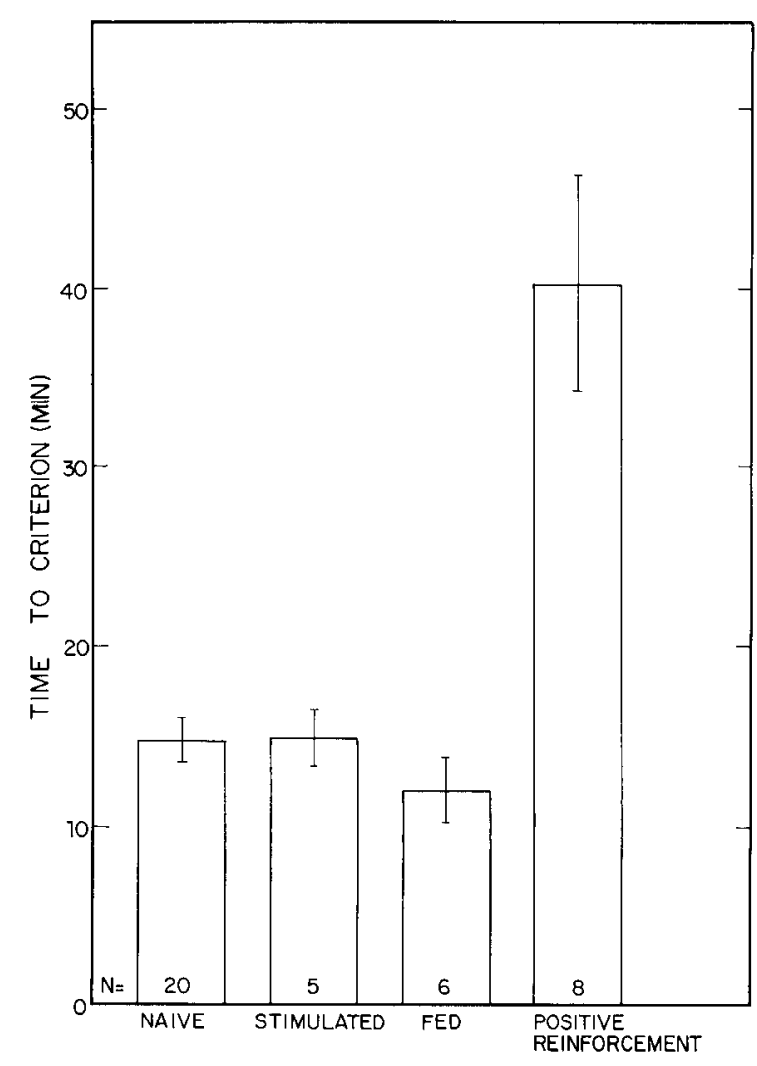

Figure 20. Time to criterion on inedible netted L/va in four groups of $A$. oculifera: Naive, previously inexperienced animals; Stimulated, 3 $\mathrm{d}$ before training with inedible netted Ulva, the lips were stimulated for a time period longer than that during training, but food was withdrawn at the response, preventing food entry; Fed, $3 \mathrm{~d}$ before training with inedible netted $U l v a$, animals were fed a quantity of regular, non-netted Ulva similar to the quantity eaten during positive reinforcement; Positive Reinforcement, $3 \mathrm{~d}$ before training with inedible Ulva, animals received a training session on edible netted Ulva. Number of animals in each group is shown $(N)$, as are SE.

identification of different foods are likely to be present on the sensory side of neural systems controlling feeding. Lack of generalization suggests that such networks may independently convey information to motor systems, with relatively little interaction between them.

Increased responsiveness after successful food consumption has previously been observed in Aplysia by Susswein et al. (1984c), who showed that swallowing small quantities of food enhances subsequent feeding. In addition, Carefoot (1967) demonstrated that Aplysia prefer to eat foods that they have successfully eaten in the past. These studies did not examine whether increased responsiveness after food consumption was specific to pairing food entry and feeding responses.

Decreased responsiveness to food has been observed previously in various gastropods. Decreased feeding after combined stimulation of the lips and interior of the buccal cavity has been reported in Ariolimax (Senseman, 1978), Aplysia vaccaria (Lickey, 1968), and Navanax (Susswein and Bennett, 1979), but these studies did not examine whether response decrement was specific to a particular food or to pairing of food with internal stimuli.

A stimulus-specific decline in behavior occurs after pairing a spccific food with noxious stimuli in Limax (Gelperin, 1975; Sahley et al., 1981a, b) and in Pleurobranchaea (Davis et al., 1980). In the gill and siphon withdrawal reflex of Aplysia, habituation is specific to the pathway stimulated (Carew et al., 1971). Differential conditioning can also be achieved, by pairing 
a shock to the tail with stimulation of either the siphon or the mantle shelf (Carew et al., 1983). Specificity to the stimulated pathway reflects independence of sensory channels conveying information to gill and siphon motoneurons (Byrne et al., 1974, 1978; Carew et al., 1971). Primary mechanoreceptors responding to touching of the lips also independently process and pass on information to buccal interneurons (Rosen et al., 1979, 1982a, b). Lack of interaction between sensory pathways may also underlie stimulus-specific decrement in feeding.

The present study has demonstrated that feeding in Aplysia is modified by pairing the behavior with reinforcing consequences. Feeding is a complex motor act, which can be modified by a number of processes (Kupfermann, 1974). The neural basis of some of these processes has been examined (Weiss ct al., 1981). To begin to examine the neural basis of learning in the feeding system of Aplysia, it would be useful to determine the extent to which common mechanisms underlie regulation of feeding by learning and other processes. The following paper (Schwarz and Susswein, 1986) will examinc this point.

\section{References}

Alexander, J. E., T. E. Audesirk, and G. J. Audesirk (1982) Rapid nonaversive conditioning in a freshwater gastropod. II. Effects of temporal relationships on learning. Behav. Neural Biol. 36: 391-402.

Alkon, D. L. (1980) Cellular analysis of a gastropod (Hermissenda crassicornis) model of associative learning. Biol. Bull. 159: 505-560.

Audesirk, T. E., J. E. Alexander, G. J. Audesirk, and C. M. Moyer (1982) Rapid, nonaversive conditioning in a freshwater gastropod I. Effects of age and motivation. Behav. Neural Biol. 36: 379-390.

Benjamin, P. R., and R. M. Rose (1979) Central generation of bursting in the feeding system of the snail, Lymnaea stagnalis. J. Exp. Biol. 80: 119-135.

Byrne, J., V. F. Castellucci, and E. R. Kandel (1974) Receptive fields and response properties of mechanoreceptor neurons innervating siphon skin and mantle shelf in Aplysia. J. Neurophysiol. 37: 10411064.

Byrne, J., V. F. Castellucci, and E. R. Kandel (1978) Contribution of individual mechanoreceptor sensory neurons to defensive gill-withdrawal reflex in Aplysia. I. Neurophysiol. 41: 418-431.

Carefoot, T. H. (1967) Growth and nutrition of Aplysia punctata feeding on a variety of marine algae. J. Mar. Biol. Assoc. U.K. 47: 556589.

Carew, T. J., V. F. Castellucci, and E. R. Kandel (1971) An analysis of dishabituation and sensitization of the gill-withdrawal reflex in Aplysia. Int. J. Neurosci. 2: 79-98.

Carew, T. J., E. T. Walters, and E. R. Kandel (1981) Classical conditioning in a simple withdrawal reflex in Aplysia californica. J. Neurosci. I: $1426-1437$

Carew, T. J., R. D. Hawkins, and E. R. Kandel (1983) Differential classical conditioning of a defensive withdrawal reflex in Aplysia californica. Science 219: 397-400.

Chang, J. J., and A. Gelperin (1980) Rapid taste-aversion learning by an isolated mulluscan CNS. Proc. Natl. Acad. Sci. USA 77: 62046206.

Cohen, J. L., K. R. Weiss, and I. Kupfermann (1978) Motor control of buccal muscles in Aplysia. J. Neurophysiol. 41: 157-180.

Crow, T. (1983) Conditioned modification of locomotion in Hermissenda crassicornis: Analysis of time-dependent associative and nonassociative components. J. Neurosci. 3: 2621-2628.

Crow, T. J., and D. L. Alkon (1980) Associative behavioral modification in Hermissenda: Cellular correlates. Science 209: 412-414.

Davis, W. J., and R. Gillette (1978) Neural correlates of behavioral plasticity in command neurons of Pleurobranchaea. Science 199: 801804.

Davis, W. J., G. J. Mpitsos, and M. J. Pinneo (1974) The behavioral hierarchy of the mollusc Pleurobranchaea I. The dominant position of the feeding behavior. J. Comp. Physiol. 90: 207-224.

Davis, W. J., G. J. Mpitsos, M. J. Pinneo, and J. L. Ram (1977) Modification of behavioral hierarchy in Pleurobranchaea I. Satiation and feeding motivation. J. Comp. Physiol. 117: 99-125.

Davis, W. J., R. Gillette, M. P. Kovac, R. P. Croll, and E. M. Matera (1983) Organization of synaptic inputs to paracerebral feeding com- mand interneurons of Pleurobranchaea. J. Neurophysiol. 49: 15571572 .

Davis, W. J., Y. Villet, D. Lee, M. Rigler, R. Gillette, and E. Prince (1980) Selective and differential avoidance learning in the feeding and withdrawal behavior of Pleurobranchaea californica. J. Comp. Physiol. 138: 157-165.

Gelperin, A. (1975) Rapid food-aversion learning by a terrestrial mollusc. Science 189: 567-570.

Gelperin, A. (1983) Neuroethological studies of associative learning in feeding control systems. In Neuroethology and Behavior, F. IIuber and M. Markl, eds., pp. 189-205, Springer-Verlag, Berlin.

Gelperin, A., J. J. Chang, and S. C. Reingold (1978) Feeding motor program in Limax. I. Neuromuscular correlates and control by chemosensory input. J. Neurobiol. 9: 285-300.

Gev, S., Y. Achituv, and A. J. Susswein (1984) Seasonal determinants of the life cycle in two species of Aplysia found in shallow waters along the Mediterranean coast of Israel. J. Exp. Mar. Biol. Ecol. 74: 67-83.

Jahan-Parwar, B., and S. M. Fredman (1983) Control of extrinsic feeding muscles in Aplysia. J. Neurophysiol. 49: 1481-1503.

Jahan-Parwar, B., A. H. Wilson, and S. M. Fredman (1983) Role of proprioceptive reflexes in control of feeding muscles of Aplysia. J. Neurophysiol. 49: 1469-1480.

Kandel, E. R., and J. H. Schwartz (1982) Molecular biology of learning: Modulation of transmitter release. Science 218: 433-443.

Kater, S. (1974) Feeding in Helisoma trivolis: The morphological and physiological basis of a fixed action pattern. Am. Zool. 14: 10171036.

Konorski, J. (1967) Integrative Activity of the Brain, U. Chicago, Chicago.

Kupfermann, I. (1974) Feeding in Aplysia: A simple system for the study of motivation. Behav. Biol. 10:1-26.

Kupfermann, I., and T. J. Carew (1974) Behavioral patterns of Aplysia californica in its natural environment. Behav. Biol. 12: 317-337.

Kupfermann, I., and K. R. Weiss (1982) Activity of an identified serotonergic neuron in freely moving Aplysia correlates with behavioral arousal. Brain Res. 241: 334-337.

Kuslansky, B., K. R. Weiss, and I. Kupfermann (1978) A neural pathway mediating satiation of feeding behavior in Aplysia. Behav. Biol 23: $230-237$.

Lee, R. M., M. R. Robbins, and R. Palovcik (1974) Pleurobranchaea behavior: Food finding and other aspects of feeding. Behav. Biol. 12 297-315.

Lickey, M. E. (1968) Learned behavior in Aplysia vaccaria. J. Comp. Physiol. Psychol. 66: 712-718.

Lorenz, K. Z. (1982) The Foundations of Fthology-The Principal Ideas and Discoveries in Animal Behavior, Touchstone, New York.

Lukowiak, K., and C. Sahley (1981) The in vitro classical conditioning of the gill-withdrawal reflex of Aplysia californica. Science 188: 954957.

Mackintosh, N. J. (1973) The Psychology of Animal Learning, Academic, New York.

Mpitsos, G. J., and S. Collins (1975) Learning: Rapid aversive conditioning in the gastropod mollusc Pleurobranchaea. Science 188: 954-957.

Preston, R. J., and R. M. Lee (1973) Feeding behavior in Aplysia californica: Role of chemical and tactile stimuli. J. Comp. Physiol. Psychol. 82: 361-381.

Reingold, S. C., and A. Gelperin (1980) Feeding motor programme in Limax: II. Modulation by sensory inputs in intact animals and isolated central nervous systems. J. Exp. Biol. 85: 1-20.

Rescorla, R. A., and R. L. Solomon (1967) Two-process learning theory: Relationships between Pavlovian conditioning and instrumental learning. Psychol. Rev. 74: 151-182.

Reynolds, G. S. (1975) A Primer of Operant Conditioning, 2nd ed., Scott Foresman, Glenview, IL.

Rose, R. M., and P. R. Benjamin (1979) The relationship of the central motor pattern to the feeding cycle of Lymnaea stagnalis. J. Exp. Biol. 80: $127-163$

Rosen, S. C., K. R. Weiss, and I. Kupfermann (1979) Response properties and synpatic connections of mechanoafferent neurons in cerebral ganglion of Aplysia. J. Neurophysiol. 42: 954-974.

Rosen, S. C., K. R. Weiss, J. L. Cohen, and I. Kupfermann (1982a) Interganglionic cerebral-buccal mechanoafferents of Aplysia: Receptive ficlds and synaptic connections to different classes of neurons involved in feeding behavior. J. Neurophysiol. 48: 271-288. 
Rosen, S. C., K. R. Weiss, and I. Kupfermann (1982b) Cross-modality sensory integration in the control of feeding in Aplysia. Behav. Neural Biol. 35: 56-63.

Sahley, C., A. Gelperin, and J. W. Rudy (1981a) One-trial associative learning modifies food preferences of a terrestrial mollusc. Proc. Natl. Acad. Sci. USA 78: 640-642.

Sahley, C., J. W. Rudy, and A. Gelperin (1981b) An analysis of associative learning in a terrestrial mollusc. I. Higher-order conditioning, blocking and a transient US pre-exposure effect. J. Comp. Physiol. 144: $1-8$.

Schwarz, M., and A. J. Susswein (1986) Identification of the neural pathway for reinforcement of feeding when Aplysia learn that food is inedible. J. Neurosci. 6: 1528-1536.

Senseman, D. M. (1978) Short-term control of food intakc by the terrestrial slug Ariolimax. J. Comp. Physiol. 124: 37-48.

Susswein, A. J., and M. V. L. Bennett (1979) Plasticity of feeding behavior in the opisthobranch mollusc Navanax. J. Neurobiol. 10 521-534

Susswein, A. J., and I. Kupfermann (1975a) Bulk as a stimulus for satiation in Aplysia. Behav. Biol. 13: 203-209.

Susswein, A. J., and I. Kupfermann (1975b) Localization of bulk stimuli underlying satiation in Aplysia. J. Comp. Physiol. 101: 309328

Susswein, A. J., and M. Schwarz (1983) A learned change of response to inedible food in Aplysia. Behav. Neural Biol. 39: 1-6.

Susswein, A. J., I. Kupfermann, and K. R. Weiss (1976) The stimulus control of biting in Aplysia. J. Comp. Physiol. 108: 75-96.

Susswein, A. J., K. R. Weiss, and I. Kupfermann (1978) The effects of food arousal on the latency of biting in Aplysia. J. Comp. Physiol. 123: $31-41$

Susswein, A. J., S. Gev, E. Feldman, and S. Markovich (1983) Activity patterns and time budgeting of Aplysia fasciata in field and laboratory conditions. Behav. Neural Biol. 39: 203-220.

Susswein, A. J., Y. Achituv, M. S. Cappell, D. C. Spray, and M. V. L.
Bennett (1984a) Pharyngeal movements during feeding sequences in Navanax inermis: A cinematographic analysis. J. Comp. Physiol. 155: 209-218.

Susswein, A. J., S. Gev, Y. Achituv, and S. Markovich (1984b) Behavioral patterns of Aplysia along the Mediterranean coast of Israel. Behav. Neural Biol. 41: 7-22.

Susswein, A. J., K. R. Weiss, and I. Kupfermann (1984c) Internal stimuli enhance feeding behavior in the mollusc Aplysia. Behav. Neural Biol. 41: 90-95.

Walters, E. T., and J. H. Byrne (1983) Associative conditioning of single sensory neurons suggests a cellular mechanism for learning. Science 219: 405-408

Walters, E. T., T. J. Carew, and E. R. Kandel (1979) Classical conditioning in Aplysia californica. Proc. Natl. Acad. Sci. USA 76:66756679 .

Walters, E. T., T. J. Carew, and E. R. Kandel (1981) Associative learning in Aplysia. Evidence for conditioned fear in an invertebrate. Science 211: 504-506.

Weiss, K. R., J. L. Cohen, and I. Kupfermann (1978) Modulatory control of buccal musculature by a serotonergic neuron (Metacerebral Cell) in Aplysia. J. Neurophysiol. 41: 181-203.

Weiss, K. R., D. E. Mandelbaum, M. Schonberg, and I. Kupfermann (1979) Modulation of buccal muscle contractility by the serotonergic metacerebral cells in Aplysia: Evidence for a role of cyclic adenosine monophosphate. J. Neurophysiol. 42: 791-803.

Weiss, K. R., U. T. Koch, J. Koester, D. E. Mandelbaum, and I. Kupfermann (1981) Neural and molecular mechanisms of food induced arousal in Aplysia californica. Adv. Physiol. Sci. 23: 305-344.

Willows, A. O. D. (1978) Physiology of feeding behavior in Tritonia. I. Behavior and mechanics. Mar. Behav. Physiol. 5: 115-135.

Willows, A. O. D. (1980) Physiological basis of feeding behavior in Tritonia diomedia. II. Neuronal mechanisms. J. Neurophysiol. 44: 849-861. 